\title{
Promoting self-regulated learning in preschoolers
}

\author{
Lisa Jacob', Manuela Benick², Sandra Dörrenbächer ${ }^{3}$, Franziska Perels ${ }^{4}$
}

\begin{abstract}
Self-regulated learning (SRL) is important for a person's school career and their later academic success, and it should therefore be fostered as early as possible. Nevertheless, research focusing on the promotion of SRL in preschoolers is limited. The present study aims to examine the efficacy of an SRL intervention based on a longitudinal control-group-design for preschoolers (direct-level intervention) and their kindergarten teachers (indirect-level intervention). The SRL intervention took place in either a) an autonomous learning environment, where SRL learning strategies were practiced with no special focus on the stimulation of communicative abilities or b) in a social-interactive learning environment, where SRL learning strategies were practiced while communicative abilities were stimulated. The sample consisted of 189 preschoolers $(49.5 \%$ , , $50.5 \%$, mean age: 5.6 years, $S D=.47$ years) and 30 kindergarten teachers. SRL and general self-regulation ability (gSR) served as performance measures. The results of the paired t-tests revealed an increase in SRL and gSR for preschoolers irrespective of the condition, while a group-differential intervention benefit for preschoolers (i.e. directautonomous or direct-interactive intervention) could not be confirmed by the applied repeated measures ANOVA and contrast analyses. Further, we did not find any substantial benefit from teacher intervention (i.e. indirect intervention) analysed by nonparametric Wilcoxon test. This unexpected result is discussed in light of methodical considerations. Nevertheless, the study provides important implications for future intervention studies.
\end{abstract}

\section{Article History}

Received: 4 March 2020

Accepted: 20 June 2020

\section{Keywords}

Self-regulated learning;

Self-regulation; Preschool;

Intervention

\section{Introduction}

Self-regulated learning (SRL) is defined as the ability to learn through autonomous and self-directed application of strategies (Sitzmann \& Ely, 2011). This definition implies that SRL is a) autonomous because the learner is able to select adequate learning strategies independently and b) self-directed because the learner is able to apply the selected learning strategies independently. It is regarded as a superordinate ability which is important for (elementary school) curriculum and academic performance (Blair \& Razza, 2007). SRL need to be delimited from a general self-regulation ability (gSR) which refers to general regulation processes in order to achieve goals by the regulating actions, thinking processes and feelings (Carver \& Scheier, 2011). There is empirical support for the effectiveness of SRL interventions across different age groups: pupils from elementary schools (Dignath, Buettner, \& Langfeldt, 2008; Leidinger \& Perels, 2012) and secondary schools (Glaser \& Brunstein, 2007; Souvignier \& Moklesgerami, 2006; Torrance, Fidalgo, \& García, 2007; Wagner, Dörrenbächer, \& Perels, 2014) as well as university students (Dörrenbächer \& Perels, 2016; Nückles, Hübner, \& Renkl, 2009; Shi, Frederiksen, \& Muis, 2013). Only a few

\footnotetext{
${ }^{1}$ Saarland University, Department of Educational Science, 66123 Saarbrücken, Germany, lisa.jacob@uni-saarland.de, https://orcid.org/0000-0003-3251-2257

2 Saarland University, Department of Educational Science, 66123 Saarbrücken, Germany, manuela.benick@uni-saarland.de, https://orcid.org/0000-0002-7040-9448

${ }^{3}$ Saarland University, Department of Educational Science, 66123 Saarbrücken, Germany, s.doerrenbaecher@googlemail.com, https://orcid.org/0000-0003-4054-5016

${ }^{4}$ Saarland University, Department of Educational Science, 66123 Saarbrücken, Germany, f.perels@mx.uni-saarland.de, https://orcid.org/0000-0002-8594-1031
} 
studies so far have already considered preschoolers as addressees of SRL intervention research (e.g. Dörr \& Perels, 2019b; Perels, Merget-Kullmann, Wende, Schmitz, \& Buchbinder, 2009). More research is therefore needed, because preschoolers are in a particularly sensitive stage for the acquisition of SRL. SRL should thus be encouraged as early as possible to establish favourable learning habits (e.g. planning of the learning actions by selecting and reflecting adequate learning strategies) and avoid dysfunctional ones (e.g. chaotic learning actions without checking the usefulness of applied learning strategies) (Landmann, Perels, Otto, Schnick-Vollmer, \& Schmitz, 2015). Therefore, the present study aims to construct and evaluate an SRL intervention especially for preschool children.

\section{Self-regulated Learning and General Self-Regulation Ability}

As mentioned above, a distinction must be made between SRL and gSR (Schunk, 2008). GSR can be defined as the process of purposefully directing a person's actions, thoughts and feelings towards a goal (Carver \& Scheier, 2011). This implies that gSR enables the individual to provide an adjustment in all of their life areas (Williford, Whittaker, Vitiello, \& Downer, 2013), even apart the special context of learning. While gSR describes general regulation processes, SRL represents an application-oriented concept of especially school and academic contexts. Following Bronson (2000), the development of gSR proceeds in stages in which children learn to mentally organize informational input from their living environment in order to achieve goals (Fox \& Riconscente, 2008). Increasingly improved attention and memory abilities enable children to handle limited cognitive capacities more efficiently (Wigfield, Klauda, \& Cambria, 2011). For the development of SRL, especially metacognitive processes ${ }^{1}$ are highly relevant as they are helpful to adapt the learning process continuously. They depend on neural maturation processes (Lyons \& Ghetti, 2010).

Zimmerman's social cognitive model (2000) of self-regulation includes assumptions about how the process of achieving goals can be subdivided in different phases. This social-cognitive model is often transferred to learning and, therefore, it is the theoretical framework for SRL. Following the cyclical model, the learning process follows three different phases: the forethought phase, performance phase and selfreflection phase. Different specific learning strategies are assigned to these phases. For preschoolers, we propose an adapted version of Zimmerman's (2000) model which contains SRL learning strategies appropriate to the stage of development (Dörr \& Perels, 2019b; see figure 1, Jacob, Dörrenbächer, \& Perels, 2019). The SRL learning strategies which should be considered favourably in the intervention for preschoolers are: using prior knowledge, definition of goals, self-efficacy, keeping breaks and selfmotivation, dealing with deflectors, monitoring, causal attribution and reflection.

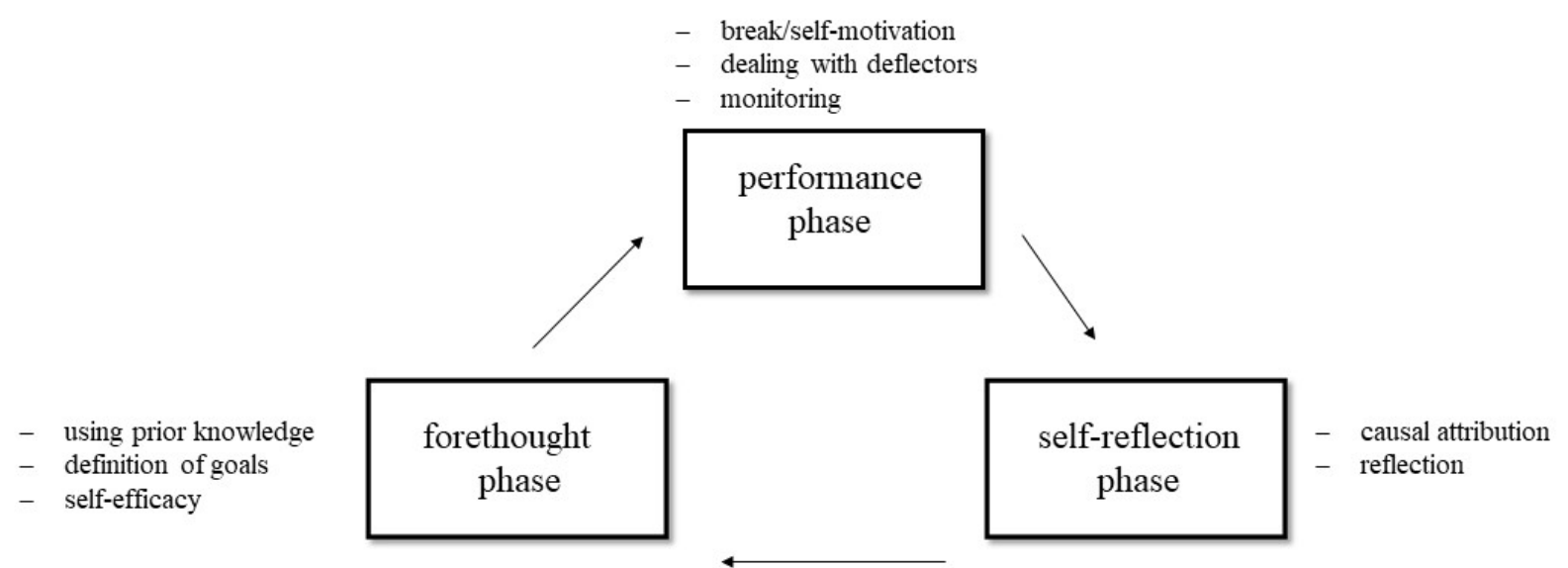

Figure 1. Zimmerman's (2000) process model of SRL, adapted for preschoolers (Jacob et al., 2019)

\footnotetext{
${ }^{1}$ Metacognition describes the availability of 'meta-information' about many different types of cognitive processes (Martinez, 2006).
} 


\section{Importance of Self-regulated Learning Interventions for Preschoolers}

In the German school system, preschoolers usually encompass 5 to 6-year-old-children which are in their last year of kindergarten. The entrance age of kindergarten is usually 3 years of age. The mission of German preschool is to prepare children for the transition of elementary school in which they usually enter with 6 years of age. But there is no standardised curriculum for preschoolers. The kind of preparation for elementary school depends on the respective kindergarten institution. Importantly for the purpose of our study, preschoolers are in a sensitive developmental period concerning the acquisition of SRL. In this period, there appears to be a general shift from an emotion-driven regulation to a more cognitive regulation where complex learning processes such as SRL can be built upon (Zelazo, 2015). Moreover, a qualitative shift from an external regulation to a more internally guided self-regulation style can be observed (see Montroy, Bowles, Skibbe, McClelland, \& Morrison, 2016). It has been demonstrated that preschool children have an elementary metacognitive understanding of their own learning processes (Lockl, Händel, Haberkorn, \& Weinert, 2016). Preschoolers are capable of goal setting and adjustment of thinking, and acting towards predefined goals (Blaye \& Chevalier, 2011; Hendry, Jones, \& Charman, 2016), which represent important abilities for the forethought phase and performance phase of SRL. In addition, preschoolers show inhibitory control (Carlson, 2005; Lewis, Reeve, Kelly, \& Johnson, 2017) and are capable of focusing their attention (Bronson, 2000; Lewis et al., 2017). Both abilities are essential for the performance phase of SRL. Lastly, preschoolers are able to reflect their own learning process (Zelazo, 2015) - an ability which is needed during the self-reflection phase of SRL. Importantly, environmental factors such as socioeconomic status can influence general child development and the development of self-regulation ability (Blair \& Raver, 2015; Dolean, Melby-Lervåg, Tincas, Damsa, \& Lervåg, 2019; Seidler \& Ritchie, 2018; Ursache \& Noble, 2016). An overarching goal in preschool is to facilitate the transition to school by providing basic social and, importantly, learning skills (e.g. Chan, 2012). Early promotion of SRL also appears advantageous because of the high neuro-cognitive plasticity in early childhood (Leisman, Mualem, \& Mughrabi, 2018). Empirical findings support the assumption that SRL and associated skills are trainable in preschool (Whitebread et al., 2005).

\section{Fostering Self-regulated Learning in Preschoolers}

For preschool age, some studies explicitly consider the SRL of young children. These include the study of Whitebread et al. (2005), in which the authors focused on 'independent learning', which has a strong overlap with SRL, in early years and analysed the pedagogical practices that foster this ability. Furthermore, Perels et al. (2009) focused on SRL in preschoolers. They used a two-level intervention approach. One level included the kindergarten teachers which were assigned to either an intervention group or a control group. The intervention was theoretically based on the process model of self-regulation (Schmitz \& Wiese, 2006), which is an adaptation of the Zimmerman (2000) model. It consisted of five intervention sessions (getting to know, pre-action phase of SRL, action phase of SRL, post-action phase of SRL, summary) in which they were taught to a) apply SRL strategies for their own learning process to be able to act as a role model and b) to support SRL in preschoolers. On the second level, preschoolers' progress in SRL was assessed before and after the teachers' intervention. The authors found an intervention benefit for kindergarten teachers as well as preschoolers. In addition, Venitz and Perels (2018) applied a two level approach to foster SRL in preschoolers. On the one level, the authors trained reference persons to a) apply SRL strategies for their own learning processes and b) to support SRL in preschool children. Altogether, the intervention consisted of three sessions (referring to the three phases of SRL). On the second level, the authors examined if the preschoolers had a benefit of the reference person's intervention. It was found that the intervention was successful on the level of preschoolers but not successful on the level of the reference persons. In a further study by Dörr and Perels (2019a), the authors aimed to improve metacognitive abilities in preschoolers and kindergarten teachers. Such metacognitive abilities are seen as important prerequisites for the acquisition of SRL (Dinsmore, Alexander, \& Loughlin, 2008). The researchers used a two-level intervention approach and found an improvement in specific metacognitive 'control activities' at the child level. In a second study, Dörr and Perels (2019b) examined the efficacy of a combination of an indirect SRL intervention (fostering reference persons) and a direct SRL intervention 
(fostering preschoolers) and could not find a significant intervention benefit concerning preschoolers' SRL performance.

In general, intervention studies for preschoolers in the context of self-regulation differ concerning a) the measurement of intervention success, either measuring benefits only at the child-level (Schmitt, McClelland, Tominey, \& Acock, 2015) or via external ratings (Dörr \& Perels, 2019a); b) the type of fostering through direct interventions at the child level (Barnett et al., 2008; Schmitt et al., 2015) or through indirect interventions which focus on the promotion of potential multipliers, such as kindergarten teachers (see also next section; Bradley, Atkinson, Tomasino, Rees \& Galvin, 2009; Ford, McDougall, \& Evans, 2009; Venitz \& Perels, 2019); and c) the general stimulation of self-regulation (Raver et al., 2011), compared to specific self-regulation strategies/aspects such as self-reflection (Espinet, Anderson, \& Zelazo, 2013; Flook, Goldberg, Pinger, \& Davidson, 2015) or metacognition (Dörr \& Perels, 2019a). However, most of the literature in this age group has tapped into gSR, and less so on SRL (e.g. Espinet et al., 2013; Flook et al., 2015; Raver et al., 2011). Indeed, gSR can be well trained at preschool age, which manifests itself in positive effects in various life areas (Perry, Hutchinson, Yee, \& Määttä, 2018) and leads to positive adaptability in school lessons (McClelland \& Cameron, 2011). However, given the positive results in SRL intervention research, it seems promising to make further efforts to develop SRL interventions for preschoolers. The current study aims to develop and evaluate an intervention design that addresses the gap in the literature as follows: a) obtaining child as well as external rating-measures, b) combining a direct with an indirect intervention approach, and c) targeting both general self-regulation ability (gSR) and specific self-regulated learning strategies (SRL).

\section{Fostering Self-regulated Learning in Kindergarten Teachers}

When comparing direct interventions on the child level and indirect interventions on the teacher level (with evaluation on the level of the students), direct interventions in school context have been shown to be more effective (Dignath et al., 2008; Otto, 2007). However, the additional application of indirect interventions can increase intervention effectiveness (Landmann et al., 2015) what is supported by empirical findings from studies that used a two-level intervention approach to foster SRL in preschoolers (Perels et al., 2009). In addition, there are some further empirical and theoretical reasons which speak for involving kindergarten teachers to foster SRL in children. First, they play an important role due to the large amount of time they spent with preschoolers (Bodrova \& Leong, 2001). Second, they have the professional task of accompanying and boosting the positive development of the children (Barnett, 2008) which should be considered in practice-oriented research. Third, mutual interaction processes between kindergarten teachers and preschoolers verifiably influence developmental processes and, respectively the acquisition of SRL, by creating a stimulating learning environment via their role model function (Bandura, 1986; Bronson, 2000) and the use of the metacognitive dialogues in which children learn to perceive and represent their learning by means of requests and informative feedback (Pramling, 1986). As a consequence, for the current study, kindergarten teachers should be involved in the SRL intervention by teaching them to support preschoolers in selecting and applying SRL learning strategies. In the present study, we promote both children (i.e. direct intervention) as well as their kindergarten teachers (i.e. indirect intervention).

\section{The Influence of Communicative Processes on Self-regulation and Self-regulated Learning}

The development of gSR takes place through the communicative interaction of the child and his/her environment (Bronson, 2000). Here, self-talk plays a prominent role (Vygotsky, 1962) and supports the planning, initiation and monitoring of actions (Winsler, Diaz, \& Montero, 1997). Self-talk can appear a) as social speech in which children communicate their thinking processes to the environment or $b$ ) as private speech in which children communicate thinking processes to themselves. With the increasing internalisation of cognitive processes, private speech transforms to inner speech while preschool age (Bono \& Bizri, 2014; Winsler, De León, Wallace, Carlton, \& Willson-Quayle, 2003). As the development of selfregulation ability is not terminated in preschool age, it is reasonable to conclude that fostering gSR, or respectively SRL, in preschoolers is also possible by encouraging social-interactive practicing in which instruction for social and private speech is given. Consequently, a social-interactive learning environment 
represents a reasonable frame for a SRL intervention for preschoolers. Autonomous practicing within an autonomous learning environment stands opposed to this. Because of the relevance of speech for selfregulation ability, studies of fostering gSR have used action accompanying language (Camp, Blom, Hebert, \& van Doorninck, 1977; Gaskins, Satlow, Pressley, \& Meltzer, 2007; Meichenbaum \& Goodman, 1971; Salmon, O'Kearney, Reese, \& Fortune, 2016). These studies have mainly built upon the learning principle of Meichenbaum and Goodman (1971). This principle postulates that adult models execute actions and verbalise aloud in a first step. In a second step, children execute the observed actions and verbalise in parallel, during intervention, children are fostered to internalise increasingly their verbalisations. In the current study, we place the SRL intervention in two different learning environments, namely a) an autonomous environment with no special focus on speech and b) a social-interactive environment with speech stimulation, following the learning principle of Meichenbaum and Goodman (1971).

\section{The Present Study}

In summary, the present study addresses the development and evaluation of an intervention for preschool children, theoretically based on the adapted SRL model of Zimmerman (2000). A direct intervention on the child-level is combined with an indirect intervention on the kindergarten-teacher-level. An SRL intervention in an autonomous learning environment (i.e. lower demands on communicative skills, e.g. preschoolers were not requested to communicate their thinking processes while doing single exercises) is compared to a social-interactive learning environment (i.e. higher demands on communicative skills; e.g. preschoolers constantly had to communicate their thinking processes to the peers while pair or group exercises). We measure any intervention benefit by using an external rating as well as a direct childappropriate measurement tool. We also compare benefits on general self-regulation abilities (gSR) with benefits on specific self-regulated learning strategies (SRL).

\section{Research Aims and Hypotheses}

Due to a) empirical evidence for the general trainability of SRL (Dörr \& Perels, 2019a; Perels et al., 2009; Whitebread et al., 2005) and b) and the existence of important developmental prerequisites in preschool age (Bronson, 2000; Lockl et al., 2016; Zelazo, 2015), the main aim of the present study is the evaluation of an SRL intervention for preschoolers.

Preschoolers' level: Because of the fundamental role of speech and communication in gSR and SRL (see the section 'Relevance of speech processes for self-regulation and SRL'), we compare the SRL intervention in two different learning environments, namely the autonomous and the social-interactive learning environments, and propose the following hypotheses:

1) The SRL intervention group (both in an autonomous and a social-interactive learning environment) shows better results in SRL and gSR at posttest after the intervention compared to the pretest.

2) The SRL intervention group (both in an autonomous and a social-interactive learning environment) shows a larger improvement in SRL and gSR than the active control group.

3) The SRL intervention group in a social-interactive learning environment stimulating communicative skills shows a stronger improvement in SRL and gSR than the SRL intervention group practicing in an autonomous learning environment.

Teachers' level: Due to the important role of kindergarten teachers in influencing preschoolers' development via their function as role models (Bandura, 1986) and in designing the critical learning environment (Barnett, 2008; Bodrova \& Leong, 2001; Bronson, 2000), the evaluation of the SRL intervention on kindergarten teacher level is also of interest, thus we hypothesise that:

4) Kindergarten teachers from the SRL intervention group (in both autonomous and socialinteractive learning environments) show better results in SRL self-report at posttest after the intervention compared to the pretest. Furthermore, those of the intervention group show better results than those of the control group. 


\section{Participants}

The child sample consisted of $\mathrm{N}=215$ preschoolers from 18 German kindergartens. 215 preschoolers participated in the pretest, whereas 189 preschoolers participated in pretest and posttest, hence representing an effective sample size. To ensure the likelihood of achieving any benefit from the intervention, the inclusion criterion was that children had to participate at least in three out of nine SRL intervention sessions 2 between pre- and posttest. The children were 5 to 6 years old $(\mathrm{M}=5.60, \mathrm{SD}=.51)$. Females numbered 106 children, and 108 children were male3. All children had normal or corrected-tonormal vision and no hearing impairment. Based on parents' statements, none of the children had a known learning disability or suffered from developmental delay. Ethical standards of research were respected. The participation in our study was voluntarily for all persons involved and we aimed at transparency in research design and methods and informed kindergarten teachers and parents about the goals and research methods of our study. The preschoolers' parents gave their written consent for participation. Data protection and safety was assured by the department. Personal data of the participants were protected by anonymization.

At the pretest, demographic information as well as control measures were collected, such as the socioeconomic status (SeS) using the book question following Bos et al. (2003) and speech competency using the 'Recognizing Terms Test' (Ricken, 2007) and the 'Passive Vocabulary Test' (Ricken, 2007). Some of those measures revealed significant baseline differences between the intervention conditions (see Table 1) and were therefore included as covariates in the statistical analyses.

Table 1. Characteristics of preschoolers by intervention condition

\begin{tabular}{|c|c|c|c|c|}
\hline & $\begin{array}{c}\text { Autonomous SRL } \\
\text { intervention (autSRL) } \\
M(S D)\end{array}$ & $\begin{array}{c}\text { Social-interactive SRL } \\
\text { intervention (intSRL) } \\
M(S D)\end{array}$ & $\begin{array}{c}\text { Active } \\
\text { control group }(C G) \\
M(S D)\end{array}$ & ANOVA $^{4}$ \\
\hline Age & $71.24(4.83)$ & $71.23(5.84)$ & $75.83(4.83)$ & $\begin{array}{c}F(2,155)=13.53 \\
p<.001\end{array}$ \\
\hline $\begin{array}{l}\text { SeS/Book } \\
\text { question }\end{array}$ & $2.31(.82)$ & $2.40(.78)$ & $2.51(.66)$ & $\begin{array}{c}F(2,210)=1.27 \\
p=.283\end{array}$ \\
\hline RT & $7.78(2.26)$ & $7.75(2.36)$ & $8.82(2.01)$ & $\begin{array}{c}F(2,156)=4.20 \\
p=.017\end{array}$ \\
\hline PV & & & & $\begin{array}{c}F(2,172)=5.91 \\
p=.003\end{array}$ \\
\hline
\end{tabular}

Note. $\mathrm{RT}=$ Recognising Terms, PV = Passive Vocabulary

Kindergartens were assigned randomly to the intervention conditions.

The Kindergarten teacher sample consisted of $N=81$ kindergarten teachers of the same 18 German kindergartens from where the preschool sample was recruited. All kindergarten teachers finished three years of vocational training as required to work as a kindergarten teacher in the relevant region of Germany. In the pretest 76 kindergarten teachers participated, whereas 36 kindergarten teachers participated in the posttest. The effective sample consisted of $n=30$ kindergarten teachers of which pretest and posttest data were available.

\footnotetext{
2 The decision for this number as criteria was data-driven. We tried to find a balance between the participation at as many sessions as possible and a as low as possible reduction of the sample.

${ }^{3}$ Due to accidental data loss, gender information cannot be declared in 13 cases.

4 The ANOVA includes 'group' as factor and age, SeS, RT and PV as dependent variables.
} 


\section{Design and Procedure}

On the level of preschoolers, the study was realised as a pretest-intervention-posttest-design with two intervention conditions and one active control group ${ }^{5}$. Pretest data were collected by two trained experimenters who participated in a multi-hour course in which a) theoretical aspects of the applied measurement instruments were explained and b) the practical application of the measurement instruments was exercised with psychology students. Further the trainers received test manuals to guarantee a standardised test instruction. At pretest, all children were tested individually, and the measurement was split into two testing occasions each to avoid overstressing the preschoolers. Each session lasted approximately 20 minutes. Given that the survey of control measures was no longer necessary at posttest, the posttest measurement covered only one session of approximately 20 minutes. The intervention was implemented in a group setting and instructed by two trainers using standardised intervention manuals. In this manual, the procedure of each intervention session was noted as well as concrete formulations which had to be used by the trainers when explaining SRL learning strategies and SRL exercises to the children. Importantly, there are two different learning environments for the SRL intervention: One group trained in an autonomous learning setting ('autSRL intervention'), whereas the second group trained in a social-interactive learning setting ('intSRL intervention'). A third group served as an active control group (CG), only performing SRL case vignettes. The study design for the intervention at child level is illustrated in Figure 2.

\begin{tabular}{|c|c|c|}
\hline $\begin{array}{l}\text { Pretest } \\
2 \text { single sessions } \\
\text { (20 minutes each) }\end{array}$ & $\begin{array}{l}\text { Intervention } \\
9 \text { resp. } 2 \text { group } \\
\text { sessions } \\
\text { ( } 45 \text { minutes each) }\end{array}$ & $\begin{array}{l}\text { Posttest } \\
1 \text { single sessions } \\
\text { (20 minutes) }\end{array}$ \\
\hline $\begin{array}{l}\text { - SRL (direct } \\
\text { test, external } \\
\text { rating) }\end{array}$ & $\begin{array}{l}- \text { AutSRL } \\
\text { intervention }\end{array}$ & $\begin{array}{l}- \text { SRL (direct } \\
\text { test, external } \\
\text { rating) }\end{array}$ \\
\hline $\begin{array}{l}\text { - General self- } \\
\text { regulation } \\
\text { ability }\end{array}$ & $\begin{array}{ll}- & \text { IntSRL } \\
& \text { intervention } \\
& \\
- & \text { Active control }\end{array}$ & $\begin{array}{l}\text { - General self- } \\
\text { regulation } \\
\text { ability }\end{array}$ \\
\hline $\begin{array}{ll}- & \text { Control } \\
& \text { measures }\end{array}$ & group & \\
\hline
\end{tabular}

Figure 2. Study design on level of preschoolers

On the teacher level, the study was realised as a pretest-intervention-posttest-design with two intervention conditions ('autSRL intervention', 'intSRL intervention') and a passive control group (CG). The pretest consisted of an SRL self-report filled in by the kindergarten teachers. The intervention consisted of an SRL workshop and the concerted application of workshop transfer materials in the regular kindergarten programme by the kindergarten teachers in parallel with the preschooler intervention period. The workshop took approximately two hours and was headed by two trained referents in kindergarten facilities. The control group did not receive any SRL input. The posttest (including self-report measurements similar to pretest) at teacher level followed after the intervention period at child level had terminated. The study design for the intervention at teacher level is illustrated in Figure 3.

\footnotetext{
${ }^{5}$ There was no passive control group because we decided for a more conservative comparison with a stronger, active control group. Further, within the German kindergarten system, it would be hard to implement a business as usual group because the preschool programs of the kindergartens vary (in Germany we do not have a standardised preschool curriculum) and are not always comparable to each other.
} 


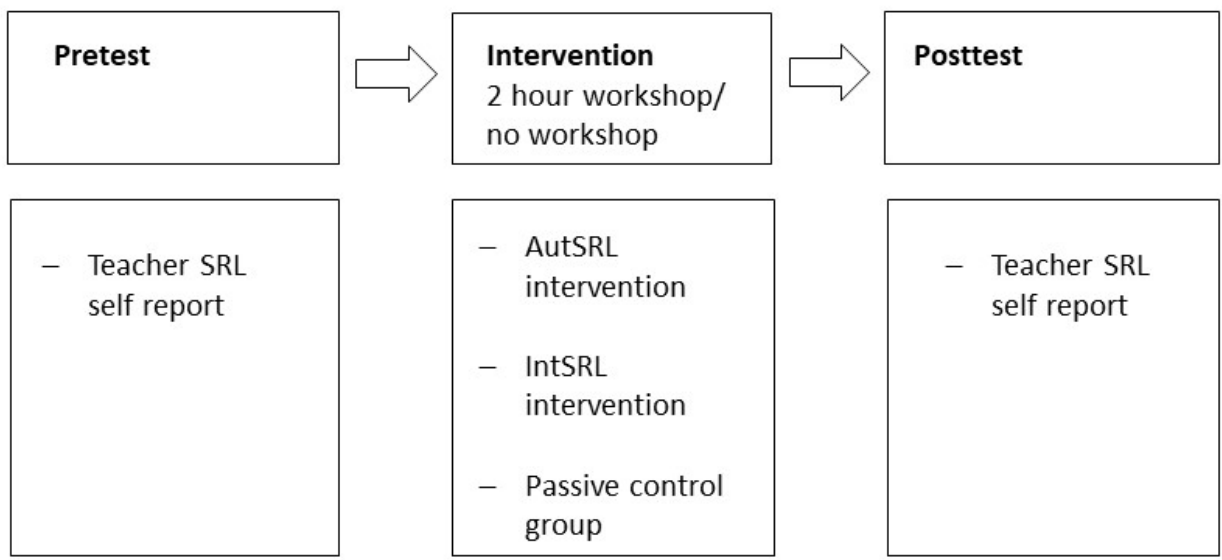

Figure 3. Study design on level of kindergarten teachers

\section{Measures}

To evaluate the efficacy of the SRL intervention at the child level, SRL was measured on child-level and by external ratings before and after the intervention. In addition, gSR was measured using an established measurement instrument.

To evaluate the efficacy of the SRL intervention at the teacher level, SRL was measured by self-report directly before and after the intervention.

\section{Measurement at the child level: Pre - and posttest measurement.}

Self-regulated learning at the child level: SRL Test. In this study, a quantitative measurement tool to assess SRL in preschoolers was applied. The tool was newly developed and first validated and optimised in a study by Jacob et al. (2019). The SRL Test is a form of multiple choice quiz and consists of 11 items with dichotomous response format (good idea vs. bad idea). Every item is presented visually in a story book, supported by colourful drawings. Children reply to the items by tapping a happy (good idea) or unhappy face (bad idea), as portrayed in the story book. Each item asks for knowledge of SRL learning strategies. The items are embedded in the narrative of the character little lion 'Lennie' of preschool age, who has the overarching goal of finding a present for his friend. On his way to goal achievement, he meets different challenges which are manageable by using certain learning strategies. An example item is shown in Figure 4. The range of total performance ranges from -11 (all items were answered incorrectly) to +11 (all items were answered correctly). Following Jacob et al. (2019), the test tool shows satisfactory test quality criterions: a) an internal consistency of $\alpha=.72, \mathrm{~b}$ ) significant validity determined by cross validation (with external SRL rating: $r=.20, p=.03$ and a direct executive functions measure on child-level: $r=.18, p=.02$ ) and c) high objectivity due to a standardised test instruction (Jacob et al., 2019). In the present study, the internal consistency was $\alpha=.65$.

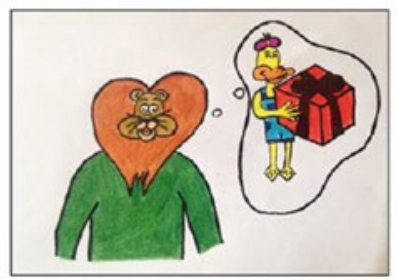

Lennie's friend Ellie the duck is coming to school soon and Lennie wants to give her something special. But what would she be happy about? Lennie thinks.

F1 How can Lennie find a great gift for Ellie? 


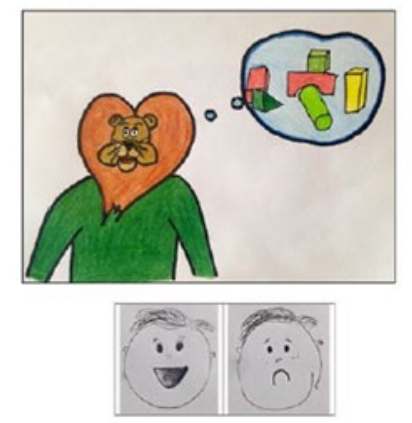

1b Lennie likes building blocks himself. That's why he wants to give Ellie building blocks. Although Ellie rarely plays with building blocks.

Figure 4. Example item of the SRL Test

Self-regulated learning at the child level: External SRL rating. The external SRL rating scale was filled out by the kindergarten teachers. On the one hand, the item pool consists of a selection of items used in two previous studies examining SRL in children (Otto, 2007; Perels et al., 2009). On the other hand, it consists of items from two established measurement tools: the Children's Independent Learning Development Checklist (CHILD 3-5) ( Whitebread et al., 2009) and the Child Behavioural Rating Scale (Rowley, 2015). Item selection is based on content considerations and the results from the item analysis of a former version of the SRL rating scale, used in Venitz and Perels (2018). All items of the composed measurement tool were rated on a four-point Likert scale ranging from 1 (never) to 4 (always). The range of total performance is between $35-140$. The external SRL rating scale contains 35 items, which are grouped into three scales and nine subscales, operationalising SRL learning strategies. The structure and reliabilities (internal consistency) of the external SRL rating scale are shown in Table 2.

Table 2. Structure and reliabilities of the external SRL rating

\begin{tabular}{|c|c|c|c|c|}
\hline SRL phase & Subscale & Example item & $\begin{array}{c}\text { Number of } \\
\text { items }\end{array}$ & Reliability \\
\hline \multirow[t]{4}{*}{$\begin{array}{l}\text { Forethought } \\
\text { phase }\end{array}$} & $\begin{array}{l}\text { Definition of goals and } \\
\text { planning }\end{array}$ & 'The child sets realistic goals.' & 7 & .88 \\
\hline & Using prior knowledge & $\begin{array}{l}\text { 'The child can apply previously learned } \\
\text { strategies.' }\end{array}$ & 2 & .76 \\
\hline & $\begin{array}{l}\text { Planning and } \\
\text { organisation }\end{array}$ & $\begin{array}{l}\text { 'The child does not complete tasks, not } \\
\text { even after receiving clues.' }\end{array}$ & 3 & .68 \\
\hline & Self-efficacy & 'The child enjoys solving problems.' & 7 & .69 \\
\hline \multirow[t]{4}{*}{$\begin{array}{l}\text { Performance } \\
\text { phase }\end{array}$} & $\begin{array}{l}\text { Breaks and self- } \\
\text { motivation }\end{array}$ & $\begin{array}{l}\text { 'The child takes a break to relax during } \\
\text { longer tasks.' }\end{array}$ & 1 & -1 \\
\hline & Keeping up & 'The child can withstand difficulties.' & 4 & .78 \\
\hline & Dealing with deflectors & 'The child is easily distracted.' & 5 & .68 \\
\hline & Monitoring & $\begin{array}{l}\text { 'The child can actively influence his/her } \\
\text { learning outcome.' }\end{array}$ & 3 & .70 \\
\hline $\begin{array}{l}\text { Self-reflection } \\
\text { phase }\end{array}$ & Reflection & $\begin{array}{l}\text { 'At the end of a task, the child checks } \\
\text { whether the result makes sense.' }\end{array}$ & 3 & .73 \\
\hline Overall & & & 35 & .80 \\
\hline
\end{tabular}

General self-regulation ability at the child level: Head-Toes-Knees-Shoulders Task. The German version of the Head-Toes-Knees-Shoulders-Task (HTKS) (Cameron et al., 2008) was applied to measure gSR. The task is divided into three sections. In section one, preschoolers learn up to two instructions ('Touch your head/toes.') and comply with the request. In addition, they are invited to name the body part they touch. In section two, children are instructed to perform in the 'opposite' manner to the previously learned instruction (to touch their head when they are instructed to 'Touch your toes' and name the body part they 
touch and vice versa). In section three, two further instructions are added ('Touch your knees/shoulders.') and a child's first task is to train these naturally by complying with the request and naming the respective body part. Subsequently, they must switch rules again and perform the 'opposite' action to all four learned instructions. The task consists of twenty trials. Action performance and naming of the touched body part are rated separately and form a total score. The range of total performance is between 0 and $80(0=$ incorrect response, $1=$ initially incorrect response that was spontaneously corrected, $2=$ correct response). The HTKS shows good psychometric quality, which is reflected by its construct validity and very strong to excellent examiner reliability ( $\kappa=.90-.98$, Connor et al., 2010; McClelland et al., 2014; $\alpha=.92$; Cameron et al., 2008). In our sample, we found an internal consistency of $\alpha=.95$.

\section{Measurement at child level: Control measurement.}

In addition, the measures used to evaluate the intervention outcome (SRL, gSR), the socioeconomic status and speech competence of the preschoolers were measured as control variables.

Socioeconomic status: Book question. In the style of Bos et al. (2003), we assessed the socioeconomic status of the children by inquiring as to the domestic book inventory. Therefore, children were asked how many books can be found in their homes. To answer, they had to tap on one of three bookshelves, as shown in Figure 5.

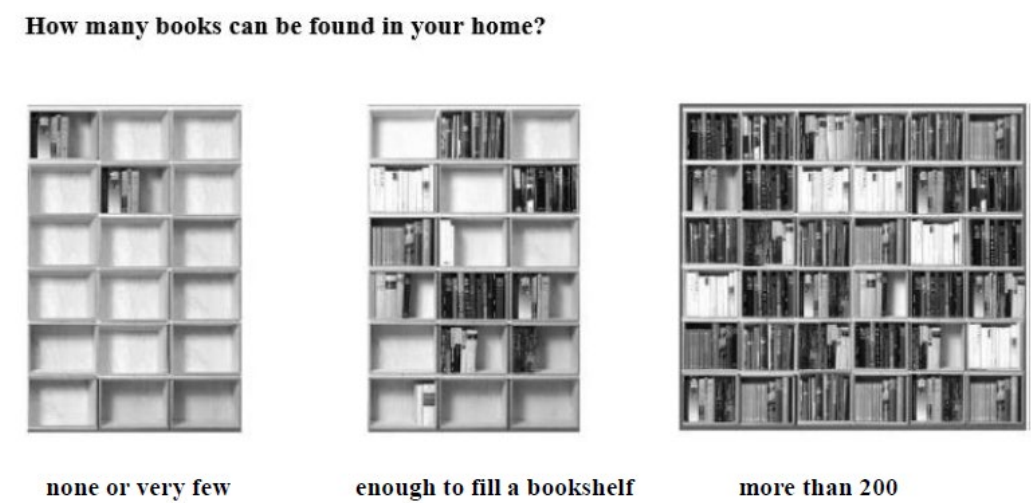

Figure 5. Book question

The total range was between 1 and $3(1=$ none or very few, $2=$ enough to fill a bookshelf, $3=$ more than 200).

Speech competence: Recognising Terms Test and Passive Vocabulary Test. Speech competence was assessed by measuring two facets: speech production and speech comprehension.

Speech production was operationalised by the Recognizing Terms Test (in German: 'Begriffe Erkennen Test', BE) which is a subtest of the German intelligence test battery for preschool age (age range: 4.0 - 6.11), namely the Hannover-Wechsler-Intelligenztest III (HAWIVA-III) (Ricken, 2007). The children's task is to generate words that fit the description of the test leader (e.g. 'Guess what I'm thinking of: It's an animal that makes meow. '). The initial 15 items are ordered in increasing difficulty. If a child answers incorrectly five times, the test is terminated. Because of the ceiling effects in a pilot study, the first three items were removed for the current study. The final instrument consists of 12 items. The range of total performance is from 0 to $12(0=$ incorrect response, $1=$ correct response; $M=8.15, S D=2.26)$. The $B E$ Test turned out to be valid and showed sufficient retest reliability $\left(r_{t t}=.86\right.$; Ricken, 2007). In our sample, we found a split-half reliability of $r=.59$.

Speech comprehension was measured by the Passive Vocabulary Test (in German; 'Passiver Wortschatz Test', PW) which is also a subtest of HAWIVA-III (Ricken, 2007). It consists of 25 stimulus cards (items). Each stimulus card shows four different images. The children are tasked with pointing at the image which fits the test leaders' description. The description contents single elements of the images (e.g. 'Show me the curly tail.' Correct image: pig). The initial 25 items are ordered in increasing difficulty. If a child 
incorrectly answers five times, the test is terminated early. Because of time-economic reasons, the first four items were deleted in the version of the test used in the current study. Nineteen items remained, for which the first items served as an example item and were not concluded in the total test score. The range of total performance is between 0 and 18 points $(0=$ incorrect response, $1=$ correct response; $M=11.52, S D=2.45)$. The PW is a valid test with a sufficient retest reliability $\left(r_{t t}=.82\right.$; Ricken, 2007). In our sample, we found a split-half reliability of $r=.55$.

\section{Measurement at child level: Intervention measurement.}

Case vignettes for preschoolers (manipulation check). The case vignettes were used as manipulation checks for preschoolers. In the case vignettes, the protagonist 'Mulle the Mole' was faced with problems in connection with the SRL learning strategy taught in the respective intervention sessions 2 to 7 . For each problem, the children were offered four possible solutions (two targets, two distractors). The children had to evaluate the quality of the solutions by drawing a happy or unhappy face ('good idea', 'bad idea') at the end of the intervention sessions. The evaluation was realised by calculating the total scores over all case vignettes. The possible performance range is between -28 (all items were answered incorrectly) and 28 points (all items were answered correctly).

\section{Measurement at teacher level.}

Self-regulated learning in kindergarten teachers (teacher SRL self-report). The questionnaire was filled out by the kindergarten teachers. It was partly constructed from questionnaires of previous projects, whereby the items were partly adopted and modified. The questionnaires of the projects SELE-F (Leidinger, 2014) and SELVES (Otto, 2007), projects to promote SRL in primary schools, and 'Krixel' (Merget-Kullmann \& Wende, 2004; see also Perels et al., 2009) and 'Kiga I' (Venitz \& Perels, 2018), a study in preschool, were used. In addition, items were constructed newly. All items were rated on a four-point Likert scale that ranges from 1 to 4 (not true/ rather not true/ rather true/ true). The teacher SRL self-report contains 75 items (range of total performance is $75-300$ ) which are grouped into two subscales: the subscale 'SRL behaviour' which captures how self-regulated teachers behave concerning different learning strategies and the subscale 'SRL mediation', which captures how SRL strategy knowledge is actively passed on to the preschoolers. The structure and reliabilities of the teacher SRL self-report are shown in Table 3.

Table 3. Structure and reliabilities of the teacher SRL self-report

\begin{tabular}{llcc}
\hline Subscale & Example items & $\begin{array}{c}\text { Number of } \\
\text { items }\end{array}$ & reliability \\
\hline SRL behaviour & 'I have clear goals for my work.' & 43 & .86 \\
& 'I always think carefully about what I want to do & & .85 \\
when I'm at work.' & & 32 & .93 \\
SRL mediation & $\begin{array}{l}\text { 'I'll show the kids how to divide bigger goals into } \\
\text { partial goals.' } \\
\text { 'If a child does not succeed in a difficult activity, } \\
\text { then we think together how it could proceed.' }\end{array}$ & 75 & .93 \\
\hline
\end{tabular}

Assessment of the application of transfer materials (manipulation check). The manipulation check was used to check if kindergarten teachers applied the transfer materials to their kindergarten routines. They should evaluate the transfer material. They stated a) how often they used it on a three-point Likert scale $(0=$ not at all/1 $=1 x / 2=$ more than $1 x)$ and $b)$ how helpful it was on a four-point Likert scale $(0=$ not helpful $/ 1=$ rather not helpful $/ 2$ = rather helpful/ 3 =helpful). For descriptive evaluation, mean scores were calculated.

\section{The Intervention}

The SRL intervention aims at the promotion of SRL strategies based on Zimmerman's (2000) model of SRL (see the section 'Self-regulated learning and general self-regulation ability'). 
SRL intervention for preschoolers. At child level, the intervention consisted of nine sessions of 45 minutes each. The group size was between 8 and 15 children. In the first session, preschoolers and trainers got to know each other and the story of 'Mulle the Mole' was introduced. The story was extended over all subsequent sessions. In sessions two to eight, the individual SRL learning strategies were taught and rehearsed. The ninth and last session served to repeat the SRL learning strategies. An overview of the SRL learning content of the individual session is shown in table 4 .

Table 4. Overview of SRL learning content and assignment to the SRL phases

\begin{tabular}{llll}
\hline Session & Learning content & SRL learning strategy & SRL phase \\
\hline 1 & Getting to know \& introduction & - & - \\
2 & 'We set ourselves goals and use our & Definition of goals, planning, Forethought \\
& knowledge!' & Using prior knowledge & Folf-efficacy \\
3 & 'We believe in ourselves!' & Breaks \& Self-motivation & Performance \\
4 & 'We're sticking to the point!' & Dealing with deflectors & Performance \\
5 & 'We keep disturbers away!' & Monitoring & Performance \\
6 & 'We're looking over our own shoulders!' & Reflection & Self-Reflection \\
7 & 'We give ourselves feedback!' & All & All \\
8 & Repetition & & \\
\hline
\end{tabular}

All intervention sessions followed the same structure. At first, the group performed a welcoming ritual. The learning strategy from the previous session was then recapped with the children. Subsequently, the narrative part introduced the relevant learning strategy of the current session. In the frame story, 'Mulle the Mole's' goal is to give a bouquet of flowers to his mum (forethought phase). For this purpose, Mulle digs a tunnel under a fence to reach a flower meadow on the other side (performance phase). Mulle reflects his action after he completes the bouquet of flowers (self-reflection phase).

In every session, a sequence of the frame story was about Mulle, who applied an SRL learning strategy to reach the overarching goal (bouquet of flowers). Subsequently, the SRL strategy was practiced by the children. The wording of the frame story differed between the two intervention conditions. A 'phase model' was used for visualisation during the reading of the frame history (see figure 6).

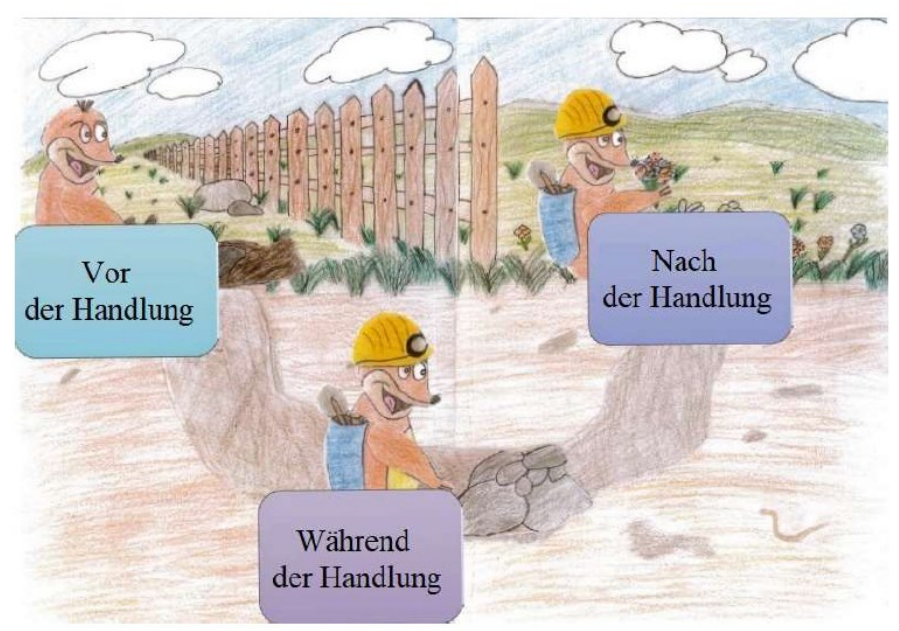

Figure 6. Phase model used for visualisation of the frame story

After the narrative part, the SRL learning strategy used by Mulle was repeated and practiced via child-appropriate exercises. These exercises differed between the two intervention conditions and focused either on autonomous or social-interactive execution. Finally, a manipulation check via case vignettes was conducted. The children received 'Mulle stickers' as a reward. The stickers showed Mulle applying the SRL learning strategy of the session. The stickers were clued on their own phase models. The session was terminated with a goodbye ritual.

Manipulation of the SRL intervention for preschoolers. Differences between the 'autSRL intervention' and the 'intSRL intervention' exist a) in the frame story. The 'autSRL intervention' included 
little spoken language, whereas the 'intSRL intervention' included a considerable amount of speech. This was realised by using verbatim speech and through the specification of guiding principles and key questions, as used by Meichenbaum and Goodman (1971). Furthermore, differences between the 'autSRL intervention' and the 'intSRL intervention' exist in b) SRL strategy exercises. In the autonomous setting, children were instructed by the trainers and subsequently performed the exercise independently. In the social-interactive setting, the execution of the SRL learning strategy was demonstrated by two trainers and subsequently practiced in peer interaction between the children. The children asked each other key questions or verbalised guiding principles, following Meichenbaum and Goodman (1971). Table 5 presents the differences in two exemplary exercises between both SRL intervention conditions in the two sessions.

Table 5. Differences two exemplary exercises between both SRL intervention conditions

\begin{tabular}{|c|c|c|c|}
\hline Session & $\begin{array}{l}\text { SRL learning } \\
\text { strategy }\end{array}$ & exercise in autSRL intervention & exercise in intSRL intervention \\
\hline 6 & Monitoring & $\begin{array}{l}\text { Flower game version A: } \\
\text { A picture with a bouquet of flowers is shown; child } \\
\text { completes parkour and collects the flowers needed } \\
\text { for the bouquet }\end{array}$ & $\begin{array}{l}\text { Flower game version B: } \\
\text { Only the quizmaster (peer) knows the } \\
\text { number and colour of flowers which are } \\
\text { required; the child has to verbally interact } \\
\text { with the quiz master to master the parkour }\end{array}$ \\
\hline 8 & Attribution & $\begin{array}{l}\text { Puppet show version A: } \\
\text { Children see two puppet shows in which } \\
\text { something goes wrong; they have to choose one of } \\
\text { two shields which should be held up high: a) } \\
\text { 'Unlucky Mulle' (external attribution) or b) 'Self- } \\
\text { Mulle'(internal attribution) }\end{array}$ & $\begin{array}{l}\text { Puppet show version B: } \\
\text { Children see two puppet shows in which } \\
\text { something goes wrong; they must explain } \\
\text { if the mistake has to be attributed externally } \\
\text { or internally; then children play the second } \\
\text { story in which something goes wrong in } \\
\text { groups of two }\end{array}$ \\
\hline
\end{tabular}

Active control group: Preschoolers. The 'intervention' in the active control group consisted of two sessions within which the children worked on the case vignettes which served as manipulation checks in the SRL intervention conditions. This means that they were taught no SRL learning strategies.

SRL intervention for kindergarten teachers. At the level of kindergarten teachers, the interventions consisted of an SRL workshop and transfer materials. The interactive workshop was held shortly prior to the child intervention. Content wise, the workshop comprised a theoretical introduction to SRL, experiences of the participants and the presentation of child-centred learning strategies. In addition, the teachers were introduced to the transfer material for each of the strategies, which was to be used in everyday kindergarten life.

Manipulation of SRL intervention for kindergarten teachers. Differences between the 'autSRL intervention' and the 'intSRL intervention' at the level of kindergarten teachers exist in a) linguistic orientation: Instructions and transfer materials for the kindergarten routine in the 'intSRL intervention' focused on verbalisation, and b) the role of speech in SRL was solely taught in the 'intSRL intervention'. In both intervention groups, short questionnaires which captured the frequency and benefit of the transfer materials were used as 'manipulation checks'.

Control group: Kindergarten teachers. There was no (workshop) intervention in the control group.

\section{Statistical Procedure}

To test hypothesis 1 , that is, whether preschool children would show a general improvement after an SRL intervention from pre- to post-test, the pretest scores of each child group (autSRL intervention, intSRL intervention, active control group) were compared to the posttest scores by using paired t-tests. The achieved scores in the SRL test, the external SRL rating (overall, subscales) and the HTKS, as a measure of gSR, served as dependent variables.

Regarding hypotheses 2 and 3, we analysed whether we would find group-differential improvement from pretest to posttest in the children's score in the SRL test, the external SRL rating (overall, subscales) and the HTKS. In the repeated measures ANOVAs, measurement time (pretest/posttest) was the repeated measures factor and group membership (autSRL intervention, intSRL intervention, active control group) 
was the between-subjects factor. We controlled for age, speech production, speech comprehension and socioeconomic status as covariates of no further interest. We further calculated directed orthogonal contrast analyses to specify any group differences: a first set of contrasts tested whether both intervention groups (autSRL intervention and intSRL intervention) would show a larger improvement than the active control group on our SRL outcome measures. A second set of contrasts tested whether the intSRL intervention group would improve significantly more than the autSRL intervention group given a potential advantage for an environment that also promotes communicative skills. As dependent variables, we used the difference-values (score posttest - score pretest). We controlled for age, speech production, speech comprehension and socioeconomic status. In addition, we compared scores in the manipulation checks between all child groups using univariate ANOVAS to examine whether the intervention per se was successfully manipulated.

Regarding hypothesis 4 , to test the effectiveness of the teacher-level intervention (i.e. indirect intervention) at the teacher level, the pretest scores of each teacher group (autSRL intervention, intSRL intervention, active control group) were compared to the posttest scores by using non-parametric Wilcoxon-Tests due to small sample sizes. The score of the teacher SRL self-report (overall, subscales) served as dependent variables. In addition, we compared scores in the manipulation checks between the teacher groups on the descriptive level to examine whether the intervention was successful.

Structure of the data. Initially, the examined data is of hierarchical structure. We have data on three levels: preschoolers, kindergarten teachers and kindergartens as institutions. A statistical analysis with the aid of multilevel analysis (see Snijders, 2011) was not feasible because preschoolers could not be matched 1:1 to a specific kindergarten teacher. In German kindergarten routines, preschoolers interact with several kindergarten teachers throughout the day. On the next higher level, however, preschoolers could be clearly assigned to kindergartens. We therefore analysed in exploratory post-hoc analyses whether membership to a certain kindergarten had an impact, and we found small Intra-Class-Correlations (ICC) (see Castro, 2002) for the dependent variables (SRL test: ICC $=0.02$, HTKS: ICC $=0.04$, external SRL rating: ICC $=0.07$ ). This means that the influence of kindergarten institutions on preschoolers' performance accounts for only $2 \%$ to $7 \%$ of variance. Based on these statistical findings, we argue that the hierarchical structure of the data on the level of kindergartens could be neglected in the present case.

Correction of multiple comparisons. To avoid false-positive results, a Bonferroni-adjusted significance level of .006 was applied for all statistical analyses on the level of the nine subscales of the external SRL rating scale (Armstrong, 2014).

\section{Results}

\section{Measurement at Child level: Manipulation Check of the Self-regulated Learning Intervention}

Preschoolers of the 'autSRL intervention' group achieved on average $M=7.45$ points ( $S D=6.68$ ). Preschoolers of the 'intSRL intervention' group achieved on average $M=5.33$ points $(S D=5.54)$. Preschoolers of the active control group achieved on average $M=6.38$ points $(S D=4.50)$. The difference between the three groups did not reach significance $(F(2,84)=.67, p=.514)$.

\section{Measurement at Child Level: Consideration of Control Variables}

The preschoolers' socioeconomic status (SeS), their age, their speech production competency and their speech comprehension competency served, if required (i.e. in the case of substantial baseline differences between groups), as control variables for the following analyses. Table 6 shows the correlations between these potential control variables and the dependent variables, as well as the correlations of dependent variables among themselves. 
Lisa JACOB et al.

Table 6. Correlations between potential control variables and dependent variables, and dependent variables among themselves

\begin{tabular}{|c|c|c|c|c|c|c|}
\hline Variable & 1 & 2 & 3 & 4 & 5 & 6 \\
\hline \multicolumn{7}{|l|}{ 1. SeS } \\
\hline 2. Age & .05 & & & & & \\
\hline 3. Speech Prod. & $.27^{* *}$ & .11 & & & & \\
\hline 4. Speech Compr. & $.25^{* *}$ & .13 & $.41^{* *}$ & & & \\
\hline 5. SRL Test & $.26^{* *}$ & .15 & $.24^{* *}$ & $.19^{*}$ & & \\
\hline 6. SRL rating & .07 & -.14 & $.17^{*}$ & .05 & .12 & \\
\hline 7. HTKS & .08 & .03 & $.31^{* *}$ & $.24^{* *}$ & $.17^{*}$ & $.17^{*}$ \\
\hline
\end{tabular}

\section{Measurement at Child Level: General Improvement from Pre- to Posttest}

The descriptive statistics for the pretest and posttest scores for the three dependent variables (SRL Test, external SRL rating, HTKS) are provided in Table 7.

In the 'autSRL intervention' group, paired $\mathrm{t}$-tests resulted in statistically significant differences between pretest- and posttest-score for the following dependent variables: SRL test, $t(61)=-11.04, p<.001$, $d=.18$, external SRL rating subscale 'using prior knowledge', $t(48)=-4.46, \mathrm{p}<.001, d=.09$, and HTKS, $t(44)$ $=2.43, p=.019, d=.05$.

In the 'intSRL intervention' group, paired t-tests resulted in statistically significant differences between pretest- and posttest-score for the SRL test, $t(63)=-9.57, p<.001, d=.15$.

In the active control group, paired t-tests resulted in statistically significant differences between pretest- and posttest-score for the following dependent variables: SRL test, $t(49)=-9.86, p<.001, d=.20$, external SRL rating overall, $t(46)=-4.84, p<.001$, external SRL rating subscales 'definition of goals', $t(46)=$ -4.84, $\mathrm{p}<.001, d=.10$, 'using prior knowledge', $t(46)=-6.04, p<.001, d=.13$, 'monitoring', $t(43)=-3.82, \mathrm{p}$ $<.001, d=.09$, reflection, $t(42)=-4.32, p<.001, d=.10$, and HTKS, $t(46)=-4.03, p<.001, d=.09$.

Table 7. Descriptive statistics of SRL Test, external SRL rating and HTKS

\begin{tabular}{|c|c|c|c|c|c|c|}
\hline & \multicolumn{2}{|c|}{ autSRL intervention } & \multicolumn{2}{|c|}{ intSRL intervention } & \multicolumn{2}{|c|}{ active control group } \\
\hline & pre $M(S D)$ & post M (SD) & pre $M(S D)$ & post M (SD) & pre $M(S D)$ & post M (SD) \\
\hline SRL Test & $-1.25(5.55)$ & $7.34(3.64)$ & $-.44(4.81)$ & $7.37(3.74)$ & $1.27(3.58)$ & $7.96(2.83)$ \\
\hline \multicolumn{7}{|l|}{$\begin{array}{c}\text { SRL rating } \\
\text { overall }\end{array}$} \\
\hline GO & $.33(1.04)$ & $.02(.90)$ & $.15(1.07)$ & $-.12(1.11)$ & $-.47(.65)$ & $.08(1.00)$ \\
\hline PK & $.21(.96)$ & $-.12(.99)$ & $.13(1.22)$ & $-.11(1.23)$ & $-.29(.75)$ & $.20(.78)$ \\
\hline PL & $.08(1.13)$ & $-.29(1.06)$ & $.23(1.03)$ & $.07(1.04)$ & $-.31(.73)$ & $.22(.84)$ \\
\hline SE & $.26(1.07)$ & .08 ( .90) & $-.08(.93)$ & - .02 (1.07) & $-.16(.97)$ & $-.06(1.04)$ \\
\hline B & $.24(.95)$ & $.01(.99)$ & $.18(1.12)$ & $.11(1.10)$ & $-.40(.80)$ & $-.11(.94)$ \\
\hline KU & $.18(1.06)$ & $.01(1.01)$ & $-.08(.93)$ & - .08 (1.10) & $-.08(.87)$ & $.05(.91)$ \\
\hline DD & $.23(1.16)$ & $-.03(.97)$ & $.08(.92)$ & $-.07(1.02)$ & $-.29(.86)$ & $.09(1.02)$ \\
\hline M & $.32(1.17)$ & $-.07(1.03)$ & $.01(.83)$ & $.01(.99)$ & $-.40(.79)$ & $.07(.99)$ \\
\hline \multirow[t]{2}{*}{$\mathrm{R}$} & $.16(.99)$ & $.05(1.01)$ & $.21(1.09)$ & $-.17(1.18)$ & $-.34(.84)$ & $.07(.94)$ \\
\hline & $.10(1.05)$ & $-.16(1.10)$ & $.15(1.16)$ & $-.05(1.09)$ & $-.24(.74)$ & $.20(.78)$ \\
\hline HTKS & 55.94 (21.78) & $67.41(16.93)$ & 58.29 (19.17) & $64.67(19.81)$ & 64.39 (15.88) & 71.35 (14.02) \\
\hline
\end{tabular}

\section{Measurement at Child level: Group-differential Improvement from Pre- to Posttest}

A repeated measures ANOVA determined that groups did not differ substantially concerning their improvement from pre- to posttest in the SRL Test score between measurements, $F(2,123)=.84, p=.43$.

However, a repeated measures ANOVA determined that groups differed statistically significantly 
Promoting self-regulated learning in preschoolers

concerning their learning growth in the external SRL rating score (overall) between measurements, $F(2,108)=6.76, p=.002$, partial $\eta^{2}=.11$.

More specifically, regarding the subscales of the external SRL rating, a repeated measures ANOVA at the univariate level determined that groups differed significantly concerning their improvement in the subscale scores 'Definition of goals and planning', $F(2,70)=6.16, p=.003$, partial $\eta^{2}=.15$, 'Using prior knowledge', $F(2,70)=6.15, p=.003$, partial $\eta^{2}=.15$, 'Keeping up', $F(2,70)=3.24, p=.045$, partial $\eta^{2}=.09$, 'Monitoring', $F(2,70)=5.40, p=.007$, partial $\eta^{2}=.13$ and 'Reflection', $F(2,70)=6.56, p=.002$, partial $\eta^{2}=.16$. The results did not reveal substantial differences between groups concerning their learning growth in the remaining four subscales scores, namely 'Planning and Organisation', $F(2,70)=.65, p=.52$, Self-efficacy', $F(2,70)=1.47, p=.24$, 'Breaks and self-motivation', $F(2,70)=.15, p=.86$, and 'Dealing with deflectors', $F(2,70)=1.28, p=.29$.

A repeated measures ANOVA determined that neither group differed concerning their learning growth in the HTKS score between measurements, $F(2,78)=.43, p=.65$.

The results of the repeated measures ANOVAs are displayed in table 8.

Table 8. Summary of the results of repeated measures ANOVAs to compare the three experimental groups (autSRL, intSRL, active control group)

\begin{tabular}{lc}
\hline & Group Differences \\
\hline SRL Test & nonsig. \\
SRL rating overall & sig. \\
definition of goals & sig. \\
using prior knowledge & sig. \\
planning and organisation & nonsig. \\
self-efficacy & nonsig. \\
breaks and self-motivation & nonsig. \\
keeping up & nonsig. \\
dealing with deflectors & nonsig. \\
monitoring & sig. \\
reflection & sig. \\
HTKS & nonsig. \\
\hline
\end{tabular}

Group-differential improvement in detail. For the external SRL rating (overall), contrast analyses showed that the intervention groups (autSRL intervention: $M=-.17, S D=1.12$, intSRL intervention: $M=$ $.18, S D=.98)$ differed statistically from the active control group $(M=.57, S D=.82)$ yet pointed in the opposite direction, with a contrast value of $-1.51(S E=.35), p<.001$. In addition, there was no statistical difference between both intervention groups, contrast value: $-.01(S E=.21), p=.97$.

For the subscale score 'Definition of goals', contrast analyses showed that the intervention groups (autSRL intervention: $M=-.21, S D=.91$, intSRL intervention: $M=-.18, S D=.72$ ) differed statistically from the active control group $(M=.44, S D=.61)$, again with a negative contrast value of $-1.27(S E=.27), p<.001$. In addition, there was no statistical difference between both intervention groups, contrast value: .03 (SE = .20), $p=.90)$.

For the subscale score 'Using prior knowledge', contrast analyses revealed that the intervention groups (autSRL intervention: $M=-.35, S D=.92$, intSRL intervention: $M=-.29, S D=.81$ ) differed statistically from the active control group $(M=.52, S D=.59)$, with an oppositely directed contrast value of -1.69 (SE= .26), $p<.001$. In addition, there was no statistical difference between both intervention groups, contrast value: $.06(S E=.19), p=.74$.

For the subscale 'Keeping up', contrast analyses demonstrated that the intervention groups (autSRL intervention: $M=-.20, S D=1.95$, intSRL intervention: $M=-.05, S D=1.64)$ differed statistically from the active control group $(M=.52, S D=1.63)$ with a negative contrast value of $-1.29(S E=.65), p=.05$. In addition, there was no statistical difference between both intervention groups, contrast value: $.15(S E=.39), p=.70$.

For the subscale score 'Monitoring', contrast analyses showed that the intervention groups (autSRL intervention: $M=-.12, S D=.80$, intSRL intervention: $M=-.21, S D=.89$ ) differed statistically from the active 
Lisa JACOB et al.

control group $(M=.40, S D=.70)$, with a negative contrast value of $-1.14(S E=.30), p<.001$. In addition, there was no statistical difference between both intervention groups, contrast value: -.09 (SE=.19), $p=.65$.

For the subscale score 'Reflection', contrast analyses indicated that the intervention groups (autSRL intervention: $M=-.12, S D=.90$, intSRL intervention: $M=-.18, S D=.73$ ) differed statistically from the active control group $(M=.38, S D=.57)$, also with a negative contrast value of $-1.06(S E=.29), p<.001$. In addition, there was no statistical difference between both intervention group, (contrast value: -.06 (SE =.18), $p=.75$.

The results concerning differences in learning growth in the external SRL rating score between the three groups are illustrated in Figure 7.

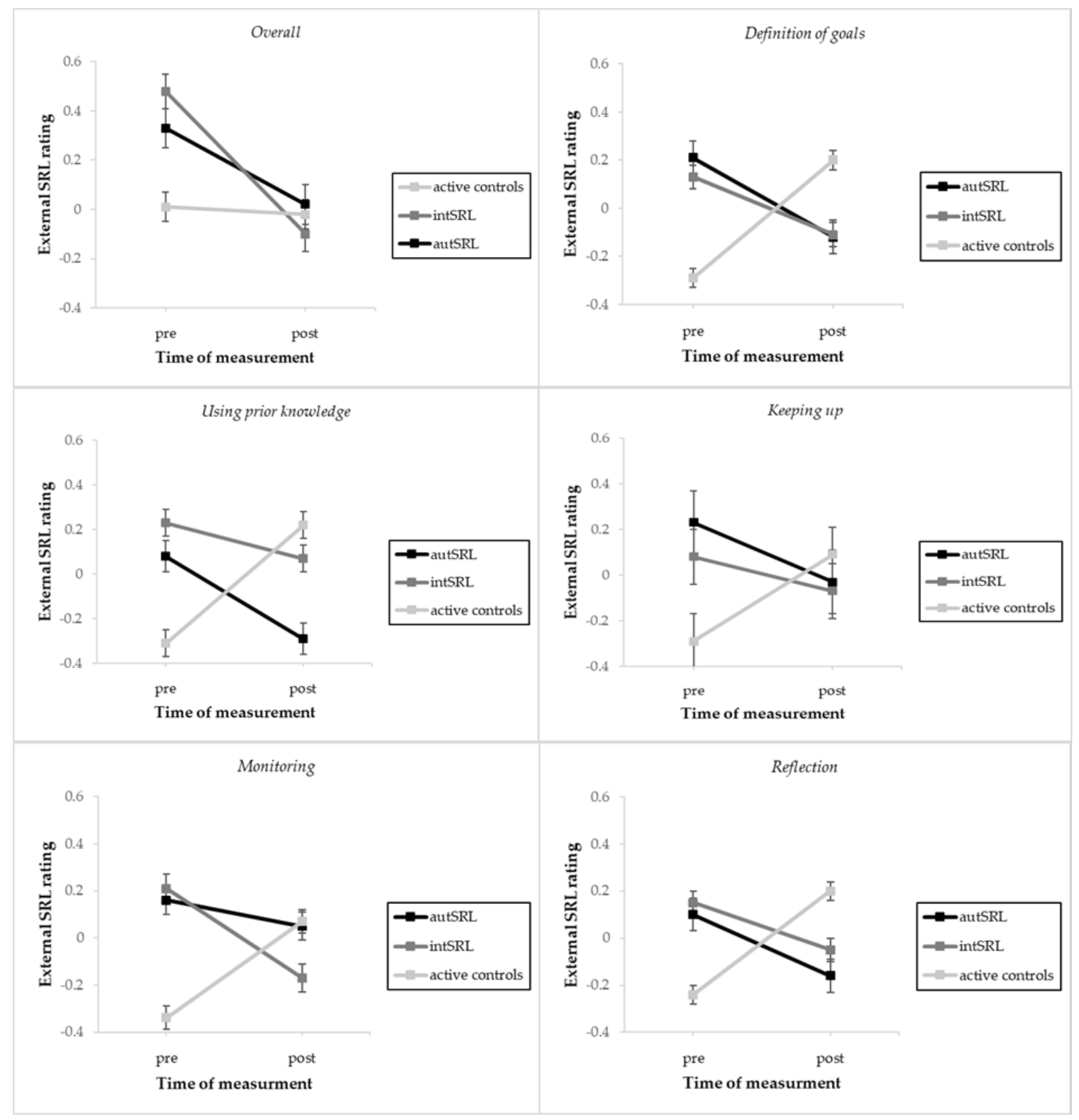

Figure 7. Differences in changes from pre- to posttest between groups for the external SRL rating score (overall, subscales)

\section{Measurement at Teacher Level: Manipulation Check of SRL Intervention}

Kindergarten teachers of the 'autSRL intervention' group $(n=7)$ reported a frequency of use of the 
Promoting self-regulated learning in preschoolers

transfer material of $M=.8$ points, $S D=.58$, and a helpfulness of transfer material of $M=2.1$ points, $S D=.16$. One Kindergarten teacher of the 'intSRL intervention' group stated a frequency of use of the transfer materials of $M=1.13$ over all material that was handed over.

\section{Measurement at Teacher Level: General Improvement from Pre- to Posttest}

To avoid a further reduction of sample size due to listwise exclusion of cases, missing values were replaced by using 'participant mean substitution'. This method turned out to be adequate in minor itemlevel missingness (Parent, 2013). The descriptive statistics for the pretest- and posttest-scores for teacher SRL self-report score (overall) as well as the subscales scores 'SRL behaviour' and 'SRL mediation' are shown in Table 9.

Table 9. Descriptive statistics of the Kindergarten teacher SRL self-report

\begin{tabular}{|c|c|c|c|c|c|c|}
\hline & \multicolumn{2}{|c|}{ autSRL Intervention } & \multicolumn{2}{|c|}{ intSRL Intervention } & \multicolumn{2}{|c|}{ Active Control Group } \\
\hline & pre $M(S D)$ & post M (SD) & pre $M(S D)$ & post M (SD) & pre $M(S D)$ & post M (SD) \\
\hline SRL self-report & $221.11(20.79)$ & $218.30(15.65)$ & $218.56(8.93)$ & 225.64 (12.97) & $226.40(17.10)$ & $228.44(16.46)$ \\
\hline SRL behaviour & 124.75 (11.64) & $123.75(8.17)$ & $124.23(5.55)$ & $127.98(9.42)$ & $132.52(9.78)$ & $134.01(11.22)$ \\
\hline SRL mediation & $96.36(10.01)$ & $94.55(8.59)$ & $94.34(5.78)$ & $97.66(6.06)$ & $101.39(8.65)$ & $101.83(7.65)$ \\
\hline
\end{tabular}

The Wilcoxon tests revealed no significant differences between pretest and posttest scores for the teacher SRL self-report (overall) in the 'autSRL intervention' ( $n=8, Z=-.68, p=.50)$, in the 'intSRL intervention' ( $n=8, Z=-1.26, p=.21)$ and in the 'passive control group' $(n=14, Z=-.56, p=.58)$. Furthermore, the Wilcoxon tests resulted in no pairwise differences between pretest and posttest score for the two subscales in the 'autSRL intervention' ('SRL behaviour': $Z=-.14, p=.89$; 'SRL mediation': $Z=-.98, p=.33$ ), in the 'intSRL intervention' ('SRL behaviour': $Z=-.71, p=.48$; 'SRL mediation': $Z=-1.86, p=.60$ ) and in the 'passive control group' ('SRL behaviour': $Z=-.51, p=.61$; 'SRL mediation': $Z=-1.25, p=.21$ ).

\section{Conclusion and Discussion}

The study aimed to evaluate the efficacy of an SRL intervention for preschool children and their kindergarten teachers. For both target groups, two intervention groups and a control group were compared. The results of the longitudinal analyses showed an increase in SRL and gSR across all conditions of preschoolers. However, the used manipulation checks indicated no effects of the SRL intervention in general, pointing to general maturational processes rather than an intervention-specific boost. Surprisingly, we found significant differences between conditions in favour of the active control group. For kindergarten teachers, we found no significant differences between groups at all.

\section{Lacking Intervention-induced Benefit in Preschoolers: Advantage of the Active Control Group}

An increase in SRL and gSR over time was revealed in all tested group conditions at the child level, whereas an intervention-specific benefit could not be obtained. Nor were there differences between our two intervention groups (i.e. 'autSRL' and 'intSRL'). Vice versa, the children of the active control group only were rated even better in SRL by their kindergarten teachers in comparison to the SRL intervention groups. In contrast, we found no differences in performance between groups in the (objective) SRL Test and the HTKS which measured gSR. This result goes contrary to our hypotheses. One explanation could concern the measurement instruments. In contrast to our study, Perels et al. (2009) fostered SRL successfully in kindergarten teachers and preschoolers. They used interview data in preschoolers and questionnaire data in kindergarten teachers to examine intervention efficacy. In addition, Dörr and Perels (2019b) reported a successful intervention to foster metacognitive skills as an important prerequisite of SRL.

As practiced in multiple research groups that deal with the assessment of young children (e.g. Bünger, Urfer-Maurer, \& Grob, 2019; Phillips \& Lonigan, 2010), we chose a multi-method approach to evaluate the effectiveness of the intervention of preschoolers. The SRL test implies that the SRL interventions did not work. This test showed a deficient internal consistency in the current study, which 
implies that its validity was restricted. Consequently, it is questionable whether the SRL test data are appropriate to detect an intervention benefit. Furthermore, the data of the external SRL rating indicated that the active control group was superior to both intervention groups. Generally, the use of external (SRL) ratings rated by kindergarten teachers which work closely with the preschoolers involves risks. First, it offers empirical evidence for a limited accuracy of teacher ratings concerning the cognitive and socioemotional abilities of their students (An, Curby, \& Brock, 2018; Mashburn \& Henry, 2004). Individual characteristics, such as work experience or self-efficacy, have an impact on the teacher ratings of young children (Furnari, Whittaker, Kinzie, \& DeCoster, 2017; Mashburn, Hamre, Downer, \& Pianta, 2006). Second, reactivity effects (Foroughi, Monfort, Paczynski, McKnight, \& Greenwood, 2016) of the active control group could have emerged. In the run up of the intervention, kindergarten teachers were informed that their preschoolers served as the control group. Perhaps the teachers rated them particularly mild to avoid presenting a poor picture of their preschoolers. Third, it is reasonable to believe that kindergarten teachers of the intervention groups were sensitised for SRL after completing the workshop. This could have led to a stricter rating of the SRL ability of the preschoolers in posttest in contrast to their SRL rating in pretest, which appears in the data as a decrease in SRL (see Figure 7). Inversely, kindergarten teachers which were part of the active control group were not sensitised and showed, therefore, more consistency in their 'rating severity'. Despite a possible sensitisation, we had important reasons for relying on the SRL rating by the kindergarten teachers, such as missing instruments at the child level which allow for crossvalidation of the developed SRL test and restricted time for capturing various other variables directly on child level.

Another critical aspect which could have led to the missing intervention benefit is the implementation of the active control group. Lipsey (1990) emphasised the role of a weakest possible control condition to achieve design sensitivity, which serves as precondition to detect benefits in intervention studies. Even though we did not explain and practice SRL learning strategies with the preschoolers of the active control group, we exposed them to those as part of our manipulation check. Potentially, the specific and compact presentation of SRL positive and SRL negative learning processes may have suggested implicit conclusions and learning effects (Christiansen, 2019; Goujon, Didierjean, \& Thorpe, 2015; Perruchet \& Pacton, 2006).

A further critical aspect is that the time interval between intervention and posttest was possibly too small to detect an intervention benefit. The learning-inhibiting effect of intervention activities is known as the mathematanical effect (Clark, 1990). This effect appears if known problem-solving strategies are in cognitive conflict with new learned strategies. To overcome the inhibition, it takes time, during which new learned learning strategies prove to be useful. In respect of preschoolers, who do not dispose of sophisticated learning strategies, more time, as well as the exercising of possibilities and success experiences, may be needed to allow intuitive or more impulsive problem-solving behaviour to pass.

Lastly, the lack of an intervention benefit of kindergarten teachers, which is discussed below, could have resulted in too little support in SRL during the kindergarten routine. This could have disrupted the consolidation of SRL strategies which preschoolers learned in the intervention sessions.

\section{Lack of an Intervention Benefit in Kindergarten Teachers}

On the level of kindergarten teachers, a passive control group instead of an active was realised to compare it with the intervention groups. However, an intervention benefit could also not be proven statistically. The three groups did not differ concerning the SRL self-report. In particular, the poor results of the manipulation check can be regarded as an indicator for the missing implementation of the transfer materials. This could have provoked not enough occupation with the topic of SRL and, in turn, missing indirect support of preschoolers' SRL skills by their kindergarten teachers. This support would have been important to consolidate SRL knowledge in daily kindergarten life. Another opposite explanation could be that the SRL workshop was useful for the teachers and helped them to generate knowledge about SRL. The sensitisation for SRL could have covered intervention benefit due to a more negative self-assessment in posttest (similar to the explanation in the section above). The inaccuracy of kindergarten teacher self-report 
of SRL was also considered as critical in the intervention study of Venitz and Perels (2019).

\section{Limitations and Outlook}

The present study has several different limitations. First, the experimental randomisation of preschoolers to intervention groups was not possible. For practical reasons, we decided to randomise the assignment of kindergartens to intervention groups. As described above, the influence of kindergarten institutions on preschoolers' performance was relatively small.

Second, the selection of kindergartens was based on geographical position. We were not able to consider variables such as pedagogical orientation, size of kindergarten or allocation of staff. Our findings are therefore representative for a certain region in Germany but do not allow for generalisation.

Third, to ensure acceptable testing economics, we assessed only a few control variables. For example, we used only one item, the book question, to measure the socioeconomic status. Beyond that, to address the question of topicality in times when people also read e-books, it could more valid to use multiple informants. Furthermore, speech competence was measured by assessing only two facets of speech: namely speech production and speech comprehension.

Fourth, we did not collect detailed information concerning the kindergarten teacher sample for data protection directive reasons. But detailed information like, for example, professional experience could have been helpful for the interpretation of our findings.

Fifth, because of time-economic reasons, we had to focus on a manageable number of measurement instruments to evaluate the SRL intervention. gSR was only assessed by the HTKS task which displays only one possible perspective on self-regulation. In contrast to the social-cognitive perspective (Bandura, 1986) on self-regulation, there also exists an developmental psychological perspective on an self-regulation which refers to regulation of emotion as characteristic of temperament (Rothbart \& Ahadi, 1994). The latter perspective could not be considered within our study but could also have an impact on learning. Although we did not find the effect we expected, the study provides a starting point for future studies and is of practical relevance for researchers. In contrast to other age groups, preschool age has not been the focus of research in the field of SRL. As described in the section 'Importance of SRL interventions for preschoolers', there are multiple arguments to consider with regards to young children. Future research could address the development and evaluation of adequate measurement instruments which are adequate for evaluating SRL interventions. Our SRL test represents an initial attempt to do so (see Jacob et al., 2019). The collection of multiple sources of information to evaluate SRL interventions should definitely be continued (Desoete, 2008). Further, we recommend to apply all measurement instruments in pretest- and posttest by means of two experimenters (as we did) and to collect data which allows for calculating an interrater reliability. This would have been an important quality criterion for the current study and could have increased the validity of our measures. In regard to cross-validation, external raters should accompany the preschoolers in everyday kindergarten life to provide more objective ratings than can be achieved by employing only kindergarten teachers that work directly with the children (An et al., 2018; Mashburn et al., 2006). For the intervention evaluation on the teacher level, it would also be advisable to rely on further data sources than only those from self-reports (Schunk, 2008).

On the level of the study design, future studies should implement a third follow-up measure which is temporally further apart from the intervention. This would offer more space for possible long-term learning effects, such as during the transition to primary school. Furthermore, an additional passive control group would increase design sensitivity and could help us to understand if manipulation checks that include SRL strategies could have led to the implicit conclusions of the preschoolers.

Besides the practical relevance for researchers in the field of SRL, the study also reveals an important outcome for educators. Dealing the topic of SRL in preschool children stresses the meaning of preschool education, especially in Germany and other countries in which no standardised curriculum is implemented so far. Additionally, the fundamental role of kindergarten teachers for a successful transition into school becomes apparent (Barnett, 2008). In this context, possible effects on the professional training of teachers 
are conceivable. Further, the assessment of SRL in preschool teachers can serve as basis for the application of SRL in kindergarten context which is of relevance when considering the model function of kindergarten teachers for preschoolers (Bandura, 1986). Further, the assessment of SRL in preschoolers could allow for the development of adaptive SRL intervention programs.

\section{Summary and Conclusion}

To summarise, it must be noted that in light of the statistical results, our applied SRL intervention for preschoolers was not efficient. We found that the active group was superior based on external SRL ratings by their kindergarten teachers. In addition, we found no indices for the effectiveness of the applied SRL intervention for kindergarten teachers, which we hypothesised would support the preschoolers' learning process. We discussed the multiple methodological aspects and reactivity effects that could have led to this result. Nevertheless, preschool age represents an important period in which to implement (SRL) learning support. Research in this field should therefore be expanded to enable the methodological difficulties which complicate the evaluation of SRL interventions for preschoolers to be addressed.

\section{Declarations}

Acknowledgements: We would like to thank Dr. Lisa Dörr and the entire team of student assistants for their help in data collection. In addition, we are grateful to M. Sc. Lena Grüneisen and M. Sc. Nathalie Zetzmann for their support in designing the intervention sessions. We would also like to thank all preschoolers and their parents as well as all kindergarten teachers for their participation and cooperation.

Authors' contributions: M. Sc. Lisa Jacob is the main writer of this manuscript and conducted the study. Dr. Manuela Benick, Dr. Sandra Dörrenbächer and Prof. Dr. Franziska Perels gave their support in writing the manuscript. Dr. Sandra Dörrenbächer and Prof. Dr. Franziska Perels also supported in the construction of the study.

Competing interests: The authors declare that they have no competing interests.

Funding: This study was funded by Deutsche Forschungsgemeinschaft (DFG) (Grant Number: PE 1176/13-2).

\section{References}

An, X., Curby, T. W., \& Brock, L. L. (2018). Is the child really what's being rated? Sources of variance in teacher ratings of socioemotional skills. Journal of Psychoeducational Assessment, 37 (7), 899 - 910. https://doi.org/10.1177/0734282918808618

Armstrong, R. A. (2014). When to use the Bonferroni correction. Ophthalmic Physiol Opt, 34, 502-508. https://doi.org/10.1111/opo.12131

Bandura, A. (1986). Social foundations of thought and action: a social cognitive theory. Englewood Cliffs, N.J.: Prentice-Hall.

Barnett, W. S. (2008). Preschool education and its lasting effects: research and policy implications. Boulder and Tempe: Education and the Public Interest Center \& Education Policy Research Unit. Retrieved May 19, 2020, from http://epicpolicy.org/publication/preschool-education-

Barnett, W. S., Jung, K., Yarosz, D. J., Thomas, J., Hornbeck, A., Stechuk, R., \& Burns, S. (2008). Educational effects of the Tools of the Mind curriculum: A randomized trial. Early Childhood Research Quarterly, 23(3), $299-313$. https://doi.org/10.1016/j.ecresq.2008.03.001

Blair, C., \& Raver, C. C. (2015). School readiness and self-regulation: A developmental psychobiological approach. Annual Review of Psychology, 66(1), 711-731. https://doi.org/10.1146/annurev-psych-010814-015221

Blair, C., \& Razza, R. P. (2007). Relating effortful control, executive function, and false belief understanding to emerging math and literacy ability in kindergarten. Child Development, 78(2), 647-663. https://doi.org/10.1111/j.1467-8624.2007.01019.x

Blaye, A., \& Chevalier, N. (2011). The role of goal representation in preschoolers' flexibility and inhibition. Journal of Experimental Child Psychology, 108(3), 469-483. https://doi.org/10.1016/j.jecp.2010.09.006

Bodrova, E., \& Leong, D. (2001). Tools of the Mind: A case study of implementing the Vygotskian approach in American early childhood and primary classrooms (UNESCO Innodata Monographs: Educational Innovations in Action No. 7). Geneva: International Bureau of Education, UNESCO.

Bono, K. E., \& Bizri, R. (2014). The role of language and private speech in preschoolers' self-regulation. Early Child Development and Care, 184(5), 658-670. https://doi.org/10.1080/03004430.2013.813846

Bos, W., Lankes, E. M., Prenzel, M., Schwippert, K., Walther, G., \& Valtin, R. (2003). Erste Ergebnisse aus IGLU. Schülerleistungen am Ende der vierten Jahrgangsstufe im internationalen Vergleich. Münster: Waxmann. 
Promoting self-regulated learning in preschoolers

Bradley, R. T., Atkinson, M., Tomasino, D., Rees, R. A., \& Galvin, P. (2009). Facilitating emotional self-regulation in preschool children: Efficacy of the Early HeartSmarts Program in promoting social, emotional and cognitive development. Institute of HeartMath. Retrieved May 19, 2020, from https://www.heartmath.org/research/research-library/educational/facilitating-emotional-selfregulation-in-preschool-children/

Bronson, M. B. (2000). Self-regulation in early childhood: Nature and nurture. New York: Guilford Press.

Bünger, A., Urfer-Maurer, N., \& Grob, A. (2019). Multimethod assessment of attention, executive functions, and motor skills in children with and without ADHD: Children's performance and parents' perceptions. Journal of attention disorders, 1087054718824985. Advance online publication. https://doi.org/10.1177/1087054718824985

Cameron, C. E., Mcclelland, M. M., Jewkes, A. M., Mcdonald, C., Farris, C. L., \& Morrison, F. J. (2008). Touch your toes! Developing a direct measure of behavioral regulation in early childhood. Early Childhood Research Quarterly, 23(2), 141-158. https://doi.org/10.1016/j.ecresq.2007.01.004

Camp, B. W., Blom, G. E., Hebert, F., \& van Doorninck, W. J. (1977). “Think Aloud”: A program for developing self-control in young aggressive boys. Journal of Abnormal Child Psychology, 5(2), 157-169. https://doi.org/10.1007/BF00913091

Carlson, S. M. (2005). Developmentally sensitive measures of executive function in preschool children. Developmental Neuropsychology, 28(2), 595-616. https://doi.org/10.1207/s15326942dn2802_3

Carver, C. S., \& Scheier, M. F. (2011). Self-regulation of action and affect. In K. D. Vohs \& R.F. Baumeister (Eds.), Handbook of selfregulation: Research, theory, and applications (2nd ed.) (pp. 3-21). New York, NY, US: Guilford Press.

Castro, S. L. (2002). Data analytic methods for the analysis of multilevel questions. A comparison of intraclass correlation coefficients, rwg(j), hierarchical linear modeling, within- and between-analysis, and random group resampling. Leadership Quarterly, 13 (1), 69-93. https://doi.org/10.1016/S1048-9843(01)00105-9

Chan, W. L. (2012). Expectations for the transition from kindergarten to primary school amongst teachers, parents and children. Early Child Development and Care, 182(5), 639-664. https://doi.org/10.1080/03004430.2011.569543

Christiansen, M. H. (2019). Implicit statistical learning: A tale of two literatures. Topics in Cognitive Science, 11(3), 468-481. https://doi.org/10.1111/tops.12332

Clark, R. E. (1990). When teaching kills learning: Studies of mathematanics. In H. Mandl, E. De Corte, N. S. Bennet, \& H. F. Friedrich (Eds.), Learning and Instruction: European research in an international context (pp. 1-22). Oxford: Pergamon Press.

Connor, C. M., Ponitz, C. C., Phillips, B. M., Travis, Q. M., Glasney, S., \& Morrison, F. J. (2010). First graders' literacy and self-regulation gains: The effect of individualizing student instruction. Journal of School Psychology, 48(5), $433-455$. https://doi.org/10.1016/j.jsp.2010.06.003

Desoete, A. (2008). Multi-method assessment of metacognitive skills in elementary school children: How you test is what you get. Metacognition and Learning, 3(3), 189-206. https://doi.org/10.1007/s11409-008-9026-0

Dignath, C., Buettner, G., \& Langfeldt, H. P. (2008). How can primary school students learn self-regulated learning strategies most effectively? A meta-analysis on self-regulation training programs. Educational Research Review, 3(2), 101-129. https://doi.org/10.1016/j.edurev.2008.02.003

Dinsmore, D. L., Alexander, P. A., \& Loughlin, S. M. (2008). Focusing the conceptual lens on metacognition, self-regulation, and selfregulated learning. Educational Psychology Review, 20(4), 391-409. https://doi.org/10.1007/s10648-008-9083-6

Dolean, D., Melby-Lervåg, M., Tincas, I., Damsa, C., \& Lervåg, A. (2019). Achievement gap: Socioeconomic status affects reading development beyond language and cognition in children facing poverty. Learning and Instruction, 63, 1-10. https://doi.org/10.1016/j.learninstruc.2019.101218

Dörr, L., \& Perels, F. (2019a). Improving metacognitive abilities as an important prerequisite for self-regulated learning in preschool children. International Electronic Journal of Elementary Education, 11(5), 449-459. https://doi.org/10.26822/iejee.2019553341

Dörr, L., \& Perels, F. (2019b). Improving young children's self-regulated learning using a combination of direct and indirect interventions. Early Child Development and Care. 1-13. https://doi.org/10.1080/03004430.2019.1595608

Dörrenbächer, L., \& Perels, F. (2016). More is more? Evaluation of interventions to foster self-regulated learning in college. International Journal of Educational Research, 78, 50-65. https://doi.org/10.1016/j.ijer.2016.05.010

Espinet, S. D., Anderson, J. E., \& Zelazo, P. D. (2013). Reflection training improves executive function in preschool-age children: Behavioral and neural effects. Developmental Cognitive Neuroscience, 4, 3-15. https://doi.org/10.1016/j.dcn.2012.11.009

Flook, L., Goldberg, S. B., Pinger, L., \& Davidson, R. J. (2015). Promoting prosocial behaviour and self-regulatory skills in preschool children through a mindfulness-based kindness curriuculum. Developmental Psychology, 51(1), 44-51. https://doi.org/10.1037/a0038256

Ford, R. M., McDougall, S. J. P., \& Evans, D. (2009). Parent-delivered compensatory education for children at risk of educational failure: Improving the academic and self-regulatory skills of a sure start preschool sample. British Journal of Psychology, 100(4), 773-797. https://doi.org/10.1348/000712609X406762 
Lisa JACOB et al.

Foroughi, C. K., Monfort, S. S., Paczynski, M., McKnight, P. E., \& Greenwood, P. M. (2016). Placebo effects in cognitive training. Proceedings of the National Academy of Sciences of the United States of America, 113(27), 7470-7474. https://doi.org/10.1073/pnas.1601243113

Fox, E., \& Riconscente, M. (2008). Metacognition and self-regulation in James, Piaget, and Vygotsky. Educational Psychology Review, 20(4), 373-389. https://doi.org/10.1007/s10648-008-9079-2

Furnari, E. C., Whittaker, J., Kinzie, M., \& DeCoster, J. (2017). Factors associated with accuracy in prekindergarten teacher ratings of students' mathematics skills. Journal of Psychoeducational Assessment, 35(4), 410-423. https://doi.org/10.1177/0734282916639195

Gaskins, I. W., Satlow, E., Pressley, M., \& Meltzer, L. (2007). Executive control of reading comprehension in the elementary school. In L. Meltzer (Ed.), Executive function in education: From theory to practice (pp. 194-215). New York: The Guilford Press.

Glaser, C., \& Brunstein, J. C. (2007). Förderung von Fertigkeiten zur Überarbeitung narrativer Texte bei Schülern der 6. Klasse. Effekte von Revisionsstrategien und selbstregulatorischen Prozeduren. Zeitschrift Fur Padagogische Psychologie, 21(1), 51-63. https://doi.org/10.1024/1010-0652.21.1.51

Goujon, A., Didierjean, A., \& Thorpe, S. (2015). Investigating implicit statistical learning mechanisms through contextual cueing. Trends in Cognitive Sciences, 19(9), 524-533. https://doi.org/10.1016/j.tics.2015.07.009

Hendry, A., Jones, E. J. H., \& Charman, T. (2016). Executive function in the first three years of life: Precursors, predictors and patterns. Developmental Review, 42, 1-33. https://doi.org/10.1016/j.dr.2016.06.005

Jacob, L., Dörrenbächer, S., \& Perels, F. (2019). A pilot study of the online assessment of self-regulated learning in preschool children: Development of a direct, quantitative measurement tool. International Electronic Journal of Elementary Education, 12(2), 115-126. https://doi.org/10.26822/iejee.2019257655

Landmann, M., Perels, F., Otto, B., Schnick-Vollmer, K., \& Schmitz, B. (2015). Selbstregulation und selbstreguliertes Lernen. In Pädagogische Psychologie. In Pädagogische Psychologie (pp. 45-65). Berlin, Heidelberg: Springer.

Leidinger, M. (2014). Förderung von Strategien selbstregulierten Lernens und deren Einfluss auf die schulische Leistung sowie die Selbstwirksamkeitsüberzeugungen von Schülern im Primarbereich: Implementation einer Lernumgebung in den regulären Unterricht der vierten Klassenstufe [Doctoral dissertation, Saarland University]. doi:10.22028/D291-23378

Leidinger, M., \& Perels, F. (2012). Training self-regulated learning in the classroom: Development and evaluation of learning materials to train self-regulated learning during regular mathematics lessons at primary school. Education Research International. 735790, 1-14. https://doi.org/10.1155/2012/735790

Leisman, G., Mualem, R., \& Mughrabi, S. K. (2018). The neurological development of the child with the educational enrichment in mind. Psicologia Educativa, 21(2), 79-96. https://doi.org/10.1016/j.pse.2015.08.006

Lewis, F. C., Reeve, R. A., Kelly, S. P., \& Johnson, K. A. (2017). Evidence of substantial development of inhibitory control and sustained attention between 6 and 8 years of age on an unpredictable Go/No-Go task. Journal of Experimental Child Psychology, 157, 6680. https://doi.org/10.1016/j.jecp.2016.12.008

Lipsey, M. R. (1990). Design sensitivity: Statistical power for experimental research. Newbury Park, CA: Sage.

Lockl, K., Händel, M., Haberkorn, K., \& Weinert, S. (2016). Metacognitive knowledge in young children: Development of a new test procedure for first graders. In H. P. Blossfeld, J. von Maurice, M. Bayer, \& J. Skopek (Eds.), Methodological Issues of Longitudinal Surveys: The Example of the National Educational Panel Study (pp. 465-485). Wiesbaden: Springer.

Lyons, K. E., \& Ghetti, S. (2010). Metacognitive development in early childhood: New questions about old assumptions. In A. Efklides \& P. Misailidi (Eds.), Trends and Prospects in Metacognition Research. Boston, MA: Springer.

Martinez, M. E. (2006). What is metacognition? Phi Delta Kappan, 87(9), 696-699. https://doi.org/10.1177/003172170608700916

Mashburn, A. J., Hamre, B. K., Downer, J. T., \& Pianta, R. C. (2006). Teacher and classroom characteristics associated with teachers' ratings of prekindergartners' relationships and behaviors. Journal of Psychoeducational Assessment, 24(4), 367-380. https://doi.org/10.1177/0734282906290594

Mashburn, A. J., \& Henry, G. T. (2004). Assessing school readiness: Validity and bias in preschool and kindergarten teachers' ratings. Educational Measurement: Issues and Practice, 23(4), 16-30. https://doi.org/10.1111/j.1745-3992.2004.tb00165.x

McClelland, M. M., \& Cameron, C. E. (2011). Self-regulation and academic achievement in elementary school children. In R. M. Lerner, J. V Lerner, E. P. Bowers, S. Lewin-Bizan, S. Gestsdottir, \& J. B. Urban (Eds.), Thriving in childhood and adolescence: The role of self-regulation processes (pp. 29-44). Newyork: John Wiley \& Sons Inc.

McClelland, M. M., Cameron, C. E., Duncan, R., Ryan, P., Acock, A. C., Miao, A., \& Pratt, M. E. (2014). Predictors of early growth in academic achievement: the head-toes-knees-shoulders task. Frontiers in Psychology, 5, 1-14. https://doi.org/10.3389/fpsyg.2014.00599

Meichenbaum, D. H., \& Goodman, J. (1971). Training impulsive children to talk to themselves: A means of developing self-control. Journal of Abnormal Psychology, 77(2), 115 - 126. https://doi.org/10.1037/h0030773 
Promoting self-regulated learning in preschoolers

Merget-Kullmann, M., \& Wende, M. (2004). Konzeption, Durchführung und Evaluation eines Erzieherinnentrainings zum Thema "Lernen lernen mit Vorschulkindern" (Unpublished doctoral dissertation) Technical University, Darmstadt.

Montroy, J. J., Bowles, R. P., Skibbe, L. E., McClelland, M. M., \& Morrison, F. J. (2016). The development of self-regulation across early childhood. Developmental Psychology, 52(11), 1744-1762. https://doi.org/10.1037/dev0000159

Nückles, M., Hübner, S., \& Renkl, A. (2009). Enhancing self-regulated learning by writing learning protocols. Learning and Instruction, 19(3), 259-271. https://doi.org/10.1016/j.learninstruc.2008.05.002

Otto, B. (2007). SELVES: Schüler-, Eltern- und Lehrertraining zur Vermittlung effektiver Selbstregulation Berlin: Logos Verlag Berlin GmbH.

Parent, M. C. (2013). Handling item-level missing data: Simpler is just as good. The Counseling Psychologist, 41(4), 568-600. https://doi.org/10.1177/0011000012445176

Perels, F., Merget-Kullmann, M., Wende, M., Schmitz, B., \& Buchbinder, C. (2009). Improving self-regulated learning of preschool children: Evaluation of training for kindergarten teachers. British Journal of Educational Psychology, 79(2), 311-327. https://doi.org/10.1348/000709908X322875

Perruchet, P., \& Pacton, S. (2006). Implicit learning and statistical learning: One phenomenon, two approaches. Trends in Cognitive Sciences, 10(5), 233-238. https://doi.org/10.1016/j.tics.2006.03.006

Perry, N. E., Hutchinson, L. R., Yee, N., \& Määttä, E. (2018). Advances in understanding young children's self-regulation of learning. In D. H. Schunck \& J. A. Greene (Eds.), Handbook of self-regulation of learning and performance (pp. 457-472). New York: Routledge.

Phillips, B. M., \& Lonigan, C. J. (2010). Child and informant influences on behavioral ratings of preschool children. Psychology in the Schools, 47(4), 374-390. https://doi.org/10.1002/pits.20476

Pramling, I. (1986). The origin of the child's idea of learning through practice. European Journal of Psychology of Education, 1(3), 31-46. https://doi.org/10.1007/BF03172629

Raver, C. C., Jones, S. M., Li-Grining, C., Zhai, F., Bub, K., \& Pressler, E. (2011). CSRP's impact on low-income preschoolers' preacademic skills: Self-regulation as a mediating mechanism. Child Development, 82(1), 362-378. https://doi.org/10.1111/j.1467-8624.2010.01561.x

Ricken, G. (2007). HAWIVA-III: Hannover-Wechsler-Intelligenztest für das Vorschulalter - III. Göttingen: Hogrefe.

Rothbart, M. K., \& Ahadi, S. A. (1994). Temperament and the development of personality. Journal of Abnormal Psychology, 103(1), 5566. https:// doi: 10.1037//0021-843x.103.1.55

Rowley, B. A. (2015). Kindergarten assessment: Analysis of the Child Behavioral Rating Scale (CBRS) (Doctoral dissertation). University of Oregon, Eugene. http://hdl.handle.net/1794/19222

Salmon, K., O'Kearney, R., Reese, E., \& Fortune, C. A. (2016). The role of language skill in child psychopathology: Implications for intervention in the early years. Clinical Child and Family Psychology Review, 19(4), 352-367. https://doi.org/10.1007/s10567-0160214-1

Schmitt, S. A., McClelland, M. M., Tominey, S. L., \& Acock, A. C. (2015). Strengthening school readiness for Head Start children: Evaluation of a self-regulation intervention. Early Childhood Research Quarterly, 30, 20-31. https://doi.org/10.1016/j.ecresq.2014.08.001

Schmitz, B., \& Wiese, B. S. (2006). New perspectives for the evaluation of training sessions in self-regulated learning: Time-series analyses of diary data. Contemporary Educational Psychology, 31(1), 64-96. https://doi.org/10.1016/j.cedpsych.2005.02.002

Schunk, D. H. (2008). Metacognition, self-regulation, and self-regulated learning: Research recommendations. Educational Psychology Review, 20(4), 463-467. https://doi.org/10.1007/s10648-008-9086-3

Seidler, A. L., \& Ritchie, S. J. (2018). The association between socioeconomic status and cognitive development in children is partly mediated by a chaotic home atmosphere. Journal of Cognition and Development, 19(5), 486-508. https://doi.org/10.1080/15248372.2018.1515077

Shi, Y., Frederiksen, C. H., \& Muis, K. R. (2013). A cross-cultural study of self-regulated learning in a computer-supported collaborative learning environment. Learning and Instruction, 23(1), 52-59. https://doi.org/10.1016/j.learninstruc.2012.05.007

Sitzmann, T., \& Ely, K. (2011). A meta-analysis of self-regulated learning in work-related training and educational attainment: What we know and where we need to go. Psychological Bulletin, 137(3), 421-442. https://doi.org/10.1037/a0022777

Snijders, T. A. B. (2011). Multilevel analysis. In L. M (Ed.), International Encyclopedia of statistical science. Berlin, Heidelberg: Springer.

Souvignier, E., \& Moklesgerami, J. (2006). Using self-regulation as a framework for implementing strategy instruction to foster reading comprehension. Learning and Instruction, 16(1), 57-71. https://doi.org/10.1016/j.learninstruc.2005.12.006

Torrance, M., Fidalgo, R., \& García, J. N. (2007). The teachability and effectiveness of cognitive self-regulation in sixth-grade writers. Learning and Instruction, 17(3), 265-285. https://doi.org/10.1016/j.learninstruc.2007.02.003 


\section{Lisa JACOB et al.}

Ursache, A., \& Noble, K. G. (2016). Neurocognitive development in socioeconomic context: Multiple mechanisms and implications for measuring socioeconomic status. Psychophysiology, 53(1), 71-82. https://doi.org/10.1111/psyp.12547

Venitz, L., \& Perels, F. (2018). Promoting self-regulated learning of preschoolers through indirect intervention: a two-level approach. Early Child Development and Care, 189(13), 1-14. https://doi.org/10.1080/03004430.2018.1434518

Venitz, L., \& Perels, F. (2019). The promotion of self-regulated learning by kindergarten teachers: Differential effects of an indirect intervention. International Electronic Journal of Elementary Education, 11(5), 437-448. https://doi.org/10.26822/iejee.2019553340

Vygotsky, L. S. (1962). Thought and language. Cambridge: MIT Press.

Wagner, D., Dörrenbächer, S., \& Perels, F. (2014). A framework for designing training programs to foster self-regulated learning and text analysis skills. Education Research International, 510342, 1-15. https://doi.org/10.1155/2014/510342

Whitebread, D., Anderson, H., Coltman, P., Page, C., Pasternak, D. P., \& Mehta, S. (2005). Developing independent learning in the early years. Education 3-13: International Journal of Primary, Elementary and Early Years Education, 33(1), 40-50. https://doi.org/10.1080/03004270585200081

Whitebread, D., Coltman, P., Pasternak, D. P., Sangster, C., Grau, V., Bingham, S., Almeqdad, Q., \& Demetriou, D. (2009). The development of two observational tools for assessing metacognition and self-regulated learning in young children. Metacognition and Learning, 4(1), 63-85. https://doi.org/10.1007/s11409-008-9033-1

Wigfield, A., Klauda, S. L., \& Cambria, J. (2011). Influences on the development of academic self-regulatory processes. In B. J. Zimmerman \& D. H. Schunk (Eds.), Handbook of self-regulation of learning and performance (pp. 33-48). New York: Routledge.

Williford, A. P., Whittaker, J. E. V., Vitiello, V. E., \& Downer, J. T. (2013). Children's engagement within the preschool classroom and their development of self-regulation. Early Education and Development, 24(2), 162-187. https://doi.org/10.1080/10409289.2011.628270

Winsler, A., De León, J. R., Wallace, B. A., Carlton, M. P., \& Willson-Quayle, A. (2003). Private speech in preschool children: Developmental stability and change, across-task consistency, and relations with classroom behaviour. Journal of Child Language, 30(3), 583-608. https://doi.org/10.1017/S0305000903005671

Winsler, A., Diaz, R. M., \& Montero, I. (1997). The role of private speech in the transition from collaborative to independent task performance in young children. Early Childhood Research Quarterly, 12(1), 59-79. https://doi.org/10.1016/S0885-2006(97)900430

Zelazo, P. D. (2015). Executive function: Reflection, iterative reprocessing, complexity, and the developing brain. Developmental Review, 38, 55-68. https://doi.org/10.1016/j.dr.2015.07.001

Zimmerman, B. J. (2000). Attaining self-regulation: A social cognitive perspective. In M. Boekarts, P. R. Pintrich, \& M. Zeidner (Eds.), Handbook of self regulation (pp. 13-41). San Diego: Acamedic Press. 